\title{
Comprehensive Evaluation on the Use of Thymus vulgaris Essential Oil as Natural Additive against Different Serotypes of Salmonella enterica
}

\author{
Abdelaziz Ed-Dra ${ }^{1,2,+}{ }^{(\mathbb{D}}$, Luca Nalbone ${ }^{2,+}{ }^{\mathbb{D}}$, Fouzia Rhazi Filali ${ }^{1}$, Najla Trabelsi ${ }^{3}$, Yassine Oulad El Majdoub ${ }^{1}$, \\ Brahim Bouchrif ${ }^{4}$, Filippo Giarratana ${ }^{2, *(1)}$ and Alessandro Giuffrida ${ }^{2}$ \\ 1 Team of Microbiology and Health, Laboratory of Chemistry-Biology Applied to the Environment, \\ Moulay Ismail University Faculty of Sciences, Zitoune, Meknes 50070, Morocco; \\ abdelaziz_iaa@yahoo.fr (A.E.-D.); fouzia.filali@yahoo.fr (F.R.F.); youladelmajdoub@unime.it (Y.O.E.M.) \\ 2 Department of Veterinary Science, University of Messina, Polo Universitario della Annunziata, \\ 98168 Messina, Italy; lnalbone@unime.it (L.N.); agiuffrida@unime.it (A.G.) \\ 3 Center of Biotechnology of Borj Cedria, LR15CBBC05 Olive Biotechnology, University of Tunis El Manar, \\ Tunis 2050, Tunisia; najlatrabe@yahoo.fr \\ 4 Laboratory of Microbiology and Hygiene of Food and Water, Pasteur Institute Morocco, 1 Place Louis Pasteur, \\ Casablanca 20100, Morocco; brahim.bouchrif@pasteur.ma \\ * Correspondence: fgiarratana@unime.it; Tel.: +39-09-03-50-37-68 \\ + These authors have contributed equally to this work.
}

Citation: Ed-Dra, A.; Nalbone, L.; Filali, F.R.; Trabelsi, N.; El Majdoub, Y.O.; Bouchrif, B.; Giarratana, F.; Giuffrida, A. Comprehensive Evaluation on the Use of Thymus vulgaris Essential Oil as Natural Additive against Different Serotypes of Salmonella enterica. Sustainability 2021, 13, 4594. https://doi.org/ $10.3390 /$ su13084594

Academic Editor: Alessandra Durazzo

Received: 18 March 2021

Accepted: 19 April 2021

Published: 20 April 2021

Publisher's Note: MDPI stays neutral with regard to jurisdictional claims in published maps and institutional affiliations.

Copyright: (C) 2021 by the authors. Licensee MDPI, Basel, Switzerland. This article is an open access article distributed under the terms and conditions of the Creative Commons Attribution (CC BY) license (https:/ / creativecommons.org/licenses/by/ $4.0 /)$.

\begin{abstract}
Essential oils were proposed as natural additives to ensure food safety and quality in a more sustainable approach. The chemical composition of Thymus vulgaris essential oil (TV-EO) collected from Morocco, its antioxidant and antimicrobial activity against different serotypes of Salmonella enterica subsp. enterica was investigated. A mathematical model was implemented to predict the Salmonella behavior when exposed to TV-EO. In situ antimicrobial activity and sensory influence were tested in minced poultry meat experimentally contaminated with Salmonella and treated with TV-EO. Hydrodistillation was used to extract TV-EO, and gas chromatography-mass spectrometry (GC-MS) analysis found thymol as the most representative compound. Results of the antioxidant activity showed an $\mathrm{IC}_{50}$ of $0.29 \pm 0.04 \mathrm{mg} / \mathrm{mL}, \mathrm{EC}_{50}$ of $0.74 \pm 0.08 \mathrm{mg} / \mathrm{mL}$, and $\mathrm{RC}_{50}$ of $0.59 \pm 0.06 \mathrm{mg} / \mathrm{mL}$. All the Salmonella strains were susceptible to TV-EO with performing results for the disc diffusion method (inhibition diameters ranged between $24 \pm 0.4 \mathrm{~mm}$ and $32 \pm 0.6 \mathrm{~mm}$ ), determination of minimum inhibitory concentration (MIC; $0.5 \%$ ) and minimum bactericidal concentration (MBC; $1 \%)$, sublethal-injured cells $(7.99 \pm 0.08 \%$ ), in situ activity (growth inhibition after 3 days), and meat sensory preservation (up to 1 week). The implemented mathematical model well fitted the Salmonella growth curve. TV-EO with significant antioxidant and antibacterial activities was suitable to ensure food safety and quality consistent with the new sustainable trends in the food field.
\end{abstract}

Keywords: Salmonella; poultry meat; thyme; antibacterial activity; food sustainability; food safety; green additives

\section{Introduction}

Nowadays, economic and demographic growth involves greater exploitation of natural resources, with an inevitable environmental impact. Therefore, more sustainable food production is needed to meet the requirements of a constantly growing world population [1]. In this scenario, several natural compounds were more frequently used in the food industry to ensure the safety and quality of foodstuffs [2].

The use of essential oils (EOs) of aromatic plants was proposed as natural additives being a suitable and sustainable alternative to the synthetic ones, thanks to their beneficial effects and safe status [3-5]. EOs are oily mixtures of different organic compounds obtained by distillation or pressing from a single type of vegetable, of which they maintain 
certain characteristics such as taste and smell [6]. Several properties of EOs have been described, including antioxidant, antimicrobial, antiparasitic, antiviral, anti-inflammatory, anti-ulcerous, and anti-carcinogenic activity [7-11]. The antimicrobial effects of EOs were tested in foods for spoilage organisms to extend their shelf-life and against foodborne pathogens to ensure their safety [12-16]. However, the use of EOs is conditioned by their influences on the organoleptic properties of foods, which are not always appreciated by consumers [5]. Therefore, the choice of EOs should be among those obtained from spices and plants commonly used in culinary preparation. In this regard, the essential oil of Thymus vulgaris (Linneo, 1753; TV-EO) represented a good compromise considering its reported antioxidant, antimicrobial, and antiparasitic effects in foods associated with pleasant organoleptic attributes $[14,17]$. In particular, inhibitory effects of TV-EO were observed against spoilage bacteria (Proteus mirabilis, Pseudomonas luteola, Enterococcus faecalis, and Serratia liquefaciens) [18], yeast (Saccharomyces cerevisiae and Zygosaccharomyces bailli) [19], and mold (Aspergillus fumigatus and Candida spp.) [20] as well as foodborne pathogens (Bacillus cereus, Yersinia spp., Pseudomonas aeruginosa; Salmonella spp., Listeria monocytogenes, Campylobacter coli, Staphylococcus aureus, and Escherichia coli O157:H7) [21,22], and zoonotic (Anisakis spp. and Trichinella spiralis) [14,23] and non-zoonotic parasites (Tetranychus cinnabarinus and Trichomonas gallinae) [24].

Worldwide, an estimated number of 600 million people fall ill after eating contaminated food, and 420,000 die every year, resulting in the loss of 33 million lives per year [25]. In this scenario, Salmonella spp. play a key role being one of the main causes of known foodborne outbreaks worldwide [26,27]. Salmonella is a ubiquitous gram-negative bacteria member of the family of Enterobacteriaceae: generally motile, facultatively anaerobic, able to infect a multitude of hosts mainly via fecal-oral route [28]. Human infection is primarily related to the consumption of contaminated water or foods, most frequently eggs and raw meat from pigs, turkeys, and chickens [29-32].

In order to ensure food safety, several authors proposed a predictive approach to study the behavior of pathogen bacteria [33,34]. Predictive microbiology can be effectively associated with new technological processes to obtain mathematical models capable of providing a useful tool in the management of food hazards.

In this scenario, this study aimed to investigate the chemical composition of TV-EO and evaluated its antioxidant activity and antibacterial effects against different serotypes of Salmonella enterica. A predictive model was implemented to study the effects of TV-EO against Salmonella based on the in vitro test results. Finally, in order to assess the in situ antimicrobial activity and the sensory influence, minced poultry meat was experimentally contaminated with Salmonella strains and then treated with different concentrations of TV-EO.

\section{Materials and Methods}

\subsection{Extraction of the Essential Oil}

Thymus vulgaris plants were collected in May 2017, from their natural habitat in the mountainous region of Ifrane (North center of Morocco) at an altitude of approximately $1530 \mathrm{~m}\left(33^{\circ} 38^{\prime} 34.0^{\prime \prime} \mathrm{N} ; 4^{\circ} 59^{\prime} 03.7^{\prime \prime} \mathrm{W}\right)$ and identified according to the procedure described by Fennane et al. [35]. Then, leaves were separated from the other parts of the plants and dried in the absence of light for one week up to 10 days. The extraction of EO was carried out by hydrodistillation in a Clevenger-type apparatus (IsoLab Laborgäte $\mathrm{GmbH}$, Wertheim, Germany). Then, the obtained EO was dried under anhydrous sodium sulfate (Sigma-Aldrich, Buchs, Switzerland) and stored in sealed glass vials at $4{ }^{\circ} \mathrm{C}$ until its use. The yield of the TV-EO (\%) was determined according to the dry matter of the plant.

\subsection{Gas Chromatography-Mass Spectrometry Analysis}

The chemical composition of TV-EO was determined using the Agilent $6890 \mathrm{~N}$ Gas Chromatograph equipped with an HP-5MS capillary column $(50 \mathrm{~m} \times 0.200 \mathrm{~mm}$ i.d., film thickness: $0.33 \mu \mathrm{m}$ ). The gas chromatography (GC) oven temperature was programmed to increase from 60 to $250{ }^{\circ} \mathrm{C}$ at a rate of $4{ }^{\circ} \mathrm{C} / \mathrm{min}$ and finally held for $15 \mathrm{~min}$. 
The transfer line temperature was $250{ }^{\circ} \mathrm{C}$. Helium was used as the carrier gas at a flow rate of $1.1 \mathrm{~mL} / \mathrm{min}$, with a split ratio equal to $1 / 100$. The quadrupole mass spectrometer was scanned over 35-465 amu, with an ionizing voltage of $70 \mathrm{eV}$ and an ionization current of $150 \mathrm{~mA}$. The percentage composition of oils was computed from the GC peak areas without correction factors. Alkane standard mixture (Sigma-Aldrich, Buchs, Switzerland) was used as calibration standard to calculate the retention index (RI). The constituents were identified by comparing their RI with those reported in the literature and the mass spectrometer (MS) with corresponding data in the computer MS libraries (NIST MS SEARCH 2.0).

\subsection{Antioxidant Activity}

The antioxidant activity of TV-EO was performed by using three different methods, including DPPH scavenging assay, reducing the power of iron (III) to iron (II), and $\beta$-carotene bleaching assay according to the protocols used by Ed-Dra et al. [13]. In this study, the concentration providing $50 \%$ inhibition $\left(\mathrm{IC}_{50}\right)$ by using DPPH scavenging assay was calculated from the curve representing the inhibition percentage and the concentrations of TV-EO, as well as the concentration providing $50 \%$ inhibition $\left(\mathrm{RC}_{50}\right)$ by using $\beta$-carotene bleaching assay was calculated by plotting inhibition percentage against the TV-EO concentrations. However, $\mathrm{EC}_{50}$, which is the effective concentration of TV-EO at which the absorbance is 0.5 , was determined by reducing the power of iron (III) to iron (II) assay.

\subsection{Antibacterial Activity}

\subsubsection{Preparation of the Strains}

The antibacterial activity of TV-EO was performed in vitro against eight different wild strains of Salmonella enterica subsp. enterica (Table 1). All the strains had been previously isolated from different meat products [30] and identified by genetic diagnosis techniques [36]. All the working cultures used in this study were prepared by inoculating a loopful from the frozen stock $\left(-80^{\circ} \mathrm{C}\right)$ in Tryptone Soya Agar (TSA; Biolife, Milan, Italy) and incubated at $37^{\circ} \mathrm{C}$ for $24 \mathrm{~h}$.

Table 1. Description of the tested strains.

\begin{tabular}{ccccc}
\hline Strains & ID Strains & Information & Serotype & Origin \\
\hline & $\mathrm{S} 1$ & MG869132* & Typhimurium & turkey sausages \\
& $\mathrm{S} 2$ & $\mathrm{KX} 355308^{*}$ & Typhimurium & turkey sausages \\
Salmonella enterica & $\mathrm{S} 3$ & $\mathrm{KX} 355300^{*}$ & Kentucky & beef sausages \\
& $\mathrm{S} 5$ & $\mathrm{KX} 355309^{*}$ & Corvallis & turkey sausages \\
& $\mathrm{S} 6$ & $\mathrm{KX} 355310^{*}$ & Kentucky & turkey sausages \\
& $\mathrm{S} 7$ & KX355311* & Saintpul & turkey sausages \\
& $\mathrm{S} 8$ & $\mathrm{KX} 3553302^{*}$ & Kentucky & turkey sausages \\
& & & Kentucky & beef sausages \\
\hline
\end{tabular}

* Accession number.

TV-EO was mixed with Tween 80 (Biolife, Milan, Italy) at a concentration of 5\% in order to facilitate its diffusion in the culture medium.

\subsubsection{Disc Diffusion Method}

Disc diffusion method was performed to preliminary test the antibacterial activity of TV-EO against the different strains of Salmonella according to a modified protocol of Mazzarino et al. [37]. A $0.5 \mathrm{McFarland}\left(10^{8} \mathrm{CFU} / \mathrm{mL}\right.$; Spectrophotometer, SmartSpec Plus, Biorad, Milan, Italy) of bacterial suspension in physiological water $(0.9 \% \mathrm{NaCl})$ was prepared and inoculated by swabbing on Mueller-Hinton Agar plates (Biolife, Milan, Italy). Ten $\mu \mathrm{L}$ of TV-EO were dropped on $6 \mathrm{~mm}$ (diameter) sterile paper discs (Biolife, Milan, Italy). A disc with $10 \mu \mathrm{L}$ of Tween 80 at a concentration of $5 \%$ was used as a negative control, while Cefotaxime ( $30 \mu \mathrm{g}$; CTX) was used as a reference test. Plates were incubated at $37^{\circ} \mathrm{C}$ for $24 \mathrm{~h}$. The inhibition diameter was measured in millimeters (disk included) and expressed as means \pm standard deviation of three replicates. The antibacterial ac- 
tivity was classified into three levels: weak (inhibition zone $\leq 12.0 \mathrm{~mm}$ ), intermediate (12.1 $\mathrm{mm} \leq$ inhibition zone $\leq 20.0 \mathrm{~mm}$ ), and strong (inhibition zone $\geq 20.1 \mathrm{~mm}$ ) [37].

\subsubsection{Determination of MIC and MBC with the Broth Dilution Method}

The minimum inhibitory concentration (MIC) of the TV-EO was assessed by microdilution assay. In sterile microtubes containing $100 \mu \mathrm{L}$ of Brain Heart Infusion (BHI; Biolife, Milan, Italy), plus $5 \%$ of Tween $80(\mathrm{BHI}+\mathrm{T})$, decreasing concentrations of TV-EO from $4 \%$ to $0.0625 \%(v / v)$, were prepared. Subsequently, $4 \mu \mathrm{L}$ of $10^{8} \mathrm{CFU} / \mathrm{g}$ bacterial suspensions were added to each tube. All suspensions were mixed and incubated at $37{ }^{\circ} \mathrm{C}$ for $24 \mathrm{~h}$. The positive control consisted of liquid media $(\mathrm{BHI}+\mathrm{T})$ without TV-EO inoculated with bacterium suspensions. Uninoculated microtubes containing liquid media $(\mathrm{BHI}+\mathrm{T})$ plus TV-EO served as the negative control. After incubation, the microtubes with the lowest concentration of TV-EO and without visible growth of bacteria were considered as the MIC. The minimum bactericidal concentration (MBC) was determined by sub-culturing samples from the microtubes on TSA incubated at $37^{\circ} \mathrm{C}$ for $24 \mathrm{~h}$. The lower concentration that did not present any growth on media was considered as the MBC.

\subsubsection{Determination of the Percentage of Sublethal-Injured Salmonella}

The percentage of sublethal-injured Salmonella was calculated according to the protocol described by Silva-Angulo et al. [38]. A Salmonella strain was inoculated in Tryptic Soy Broth (TSB; Biolife, Milan, Italy) with a concentration of TV-EO equal to the half of MIC and incubated at $37^{\circ} \mathrm{C}$ for $24 \mathrm{~h}$. Series of decimal dilutions were prepared in sterile peptone water $(8.5 \mathrm{~g} \mathrm{NaCl}, 1 \mathrm{~g}$ peptone, in $1 \mathrm{~L}$ of water), and $100 \mu \mathrm{L}$ of each dilution were plated onto TSA and TSA plus $5 \%$ of $\mathrm{NaCl}$ (TSA-S) and incubated at $37^{\circ} \mathrm{C}$ for $24-48 \mathrm{~h}$. The percentage of sublethal-injured cells was estimated using the following Equation (1):

Sublethal-injured colonies $(\%)=[1-($ Count on TSA-S/Count on TSA $)] * 100$

TSA, as generic media, supports the growth of both uninjured and injured bacteria, whereas the TSA-S, as not optimal media, supports only the growth of uninjured bacteria. Salmonella inoculated in TSB without TV-EO and plated onto TSA-S was considered as control samples. All the experiments were performed at triplicates in different times.

\subsubsection{In vitro Effect of TV-EO on the Growth of Salmonella}

The Salmonella strain S2 (the least sensible strain) was inoculated in TSB with different concentrations of TV-EO $(0 \%, 0.25 \%, 0.4 \%$, and $0.5 \%)$ and incubated both at $10{ }^{\circ} \mathrm{C}$ and $20{ }^{\circ} \mathrm{C}$. The bacterial load was periodically evaluated until the growth curve of the control samples $(0 \%$ TV-EO) reached the stationary phase. The bacterial count was performed by preparing a series of decimal dilutions in sterile peptone water, and $100 \mu \mathrm{L}$ of each dilution was pour-plated into Xylose Lysine Deoxycholate Agar (XLD; Biolife, Milan, Italy). All the plates were incubated at $37^{\circ} \mathrm{C}$ for $24 \mathrm{~h}$. All tests were performed in triplicates at different times.

\subsection{Predictive Model}

A mathematical model was implemented to predict the effects of the different concentrations of TV-EO on the in vitro growth of Salmonella enterica subsp. enterica. The predictive approach herein adopted relied on the principles proposed by Giuffrida et al. [39]. Particularly, the model was based on the introduction of a variable that takes into account the inhibiting effect of TV-EO into the primary model rather than in a secondary one. In this way, the introduced variable reproduced the antibacterial effect without interfering with growth rate and allowing to use a generical secondary model based on the main environmental variables such as temperature. The predictive model was based on the 
set of differential equations of the Baranyi and Roberts' model [40], where the bacterial concentration $\mathrm{N}$ at the time $\mathrm{t}$ is generically expressed as follows:

$$
\begin{gathered}
\mathrm{dN} / \mathrm{dt}=\mu_{\max } \mathrm{N} *[\mathrm{Q} /(1+\mathrm{Q})] *\left[1-\left(\mathrm{N} / \mathrm{N}_{\max }\right)\right] \\
\mathrm{dQ} / \mathrm{dt}=\mu_{\max } \mathrm{Q}
\end{gathered}
$$

Here $\mu_{\max }$ is the maximum specific growth rate and $\mathrm{N}_{\max }$ the theoretically maximum population densities of the bacterial population; $Q$ represents the physiological state of the species and, as expressed in Equations (2) and (3), allows to calculate the lag time duration (hours). In order to take into account the antibacterial activity of TV-EO, the term $\xi$ is introduced into Equation (2), obtaining Equation (4):

$$
\mathrm{dN} / \mathrm{dt}=\mu_{\max } \mathrm{N} *[\mathrm{Q} /(1+\mathrm{Q})] *\left[1-\left(\mathrm{N} / \mathrm{N}_{\max }\right)\right] * \xi
$$

with $\xi<1$.

In this way, the term $\xi$ reduces the concentration of $\mathrm{N}$ without interfering with the calculation of $\mu_{\max }$. The expression of the antibacterial effect is inversely proportional to the $\xi$ values.

The model was numerically solved by the Euler method, and the solver function of Microsoft Excel was used for each growth curve of each data set in order to calculate appropriate $\xi$ values related to each data set. Furthermore, for the numerical solving of Equation (5), the secondary model of Ratowsky, as modified by Gumudavelli et al. [41] for Salmonella enteritidis in egg yolk, was introduced into Equation (4) to calculate the $\mu_{\max }$ values as a function of temperature, according to the below Equation (5):

$$
\mu_{\max }=\mathrm{a}\left(\mathrm{T}-\mathrm{T}_{\min }\right)^{2}\left\{1-\exp \left[\mathrm{b}\left(\mathrm{T}-\mathrm{T}_{\max }\right)\right]\right\}
$$

with $\mathrm{a}=0.0011 ; \mathrm{b}=0.27469 ; \mathrm{T}_{\min }=6.13 ; \mathrm{T}_{\max }=46.26$.

For the resolution of the complete model (Equations (4) and (5)), the primary parameters $\mathrm{Q}_{0}$ and $\mathrm{N}_{\max }$ were obtained as follow: Particularly, $\mathrm{N}_{\max }$ was expressed by the mean value of the observed data, while $Q_{0}$ was calculated by fitting each predicted curve to the observed ones.

The effect of the $\xi$ parameter on the goodness of the prediction was evaluated by the calculation of the root-mean-squared error (RMSE). Furthermore, in order to study the relation between $\xi$ values and the percentage of TV-EO, a linear regression test was performed.

\subsection{In situ Antimicrobial Activity of TV-EO in Poultry Minced Meat}

In order to evaluate the in situ inhibition of Salmonella, about $2500 \mathrm{~g}$ of poultry minced meat was artificially contaminated with a mix of all the eight previously tested Salmonella strains. Then, the samples were divided into five parts; one was considered as a negative control without any treatment of TV-EO, whereas the other parts were mixed with TV-EO at different concentrations $(0.125 \%, 0.25 \%, 0.5 \%$, and $1 \%)$. Three batches were prepared for each concentration. Then all the samples were stored at $4{ }^{\circ} \mathrm{C}$ and analyzed periodically (up to 13 days) for the count of Enterobacteriaceae and Salmonella. For the microbiological analysis, $25 \mathrm{~g}$ of the sample were mixed with $225 \mathrm{~mL}$ of peptone water (PW; Biolife, Milan, Italy), then the series of decimal dilutions were prepared, always in PW. Enterobacteriaceae were enumerated on Violet Red Bile Glucose Agar (VRBG; Biolife, Milan, Italy) and incubated at $37^{\circ} \mathrm{C}$ for $24 \mathrm{~h}$. Salmonella was counted in XLD Agar (Biolife, Milan, Italy) after incubation at $37^{\circ} \mathrm{C}$ for $24 \mathrm{~h}$. When loads of Salmonella were lower than the detection limit of the method (10 CFU/g), the presence of Salmonella was further checked according to ISO 6579-1:2017 [42]. 


\subsection{Test on Poultry Minced Meat: Sensory Analysis}

Sensory analysis was performed according to ISO guidelines [43-45]. Six experienced panelists were chosen among the staff of the laboratory of the Inspection of Foods of Animal Origin (Department of Veterinary Sciences, Messina, Italy). These panelists had been previously trained to gain confidence with the sensory characteristics of raw and cooked minced poultry meat. Each panelist performed three different assays in separate conditions at $0,1,3,6,9$, and 13 days of storage at $4{ }^{\circ} \mathrm{C}$ for each batch of minced meat treated with different TV-EO concentrations $(0.125 \%, 0.25 \%, 0.5 \%, 1 \%)$. Untreated minced meat was used as control. Before the assessments, each sample was kept at room temperature for $20 \mathrm{~min}$. Panelists were asked to score the odor and color of the raw mince samples. For taste evaluation, each sample was cooked in a microwave $(300 \mathrm{w})$ at $180^{\circ} \mathrm{C}$ for $30 \mathrm{~min}$ and then served to the panelists. The protocol proposed by Smaoui et al. [46] was modified and used to carry out the sensory analysis based on a 10 points hedonic scale, where $10=$ like extremely, 1 = dislike extremely, and the values of 5 (neither like nor dislike) and higher were considered acceptable. Samples with scores below 5 were considered unacceptable, and the sensory analysis was stopped.

\subsection{Statistical Analysis}

All the measurements were performed in triplicate, and the results were presented as means \pm standard deviation. The differences between the effect of the TV-EO and the CTX in the disc diffusion method were statistically analyzed using the Student's $t$-test, while the effect of the TV-EO against the different strains was compared using a one-way analysis of variance (ANOVA). The in situ effects of the different concentrations of the TV-EO on the inhibition of bacteria and the sensory analysis of poultry minced meat were statistically analyzed using a one-way ANOVA test, and Fisher's least significant difference (LSD) test was used as post hoc analysis. A probability level of $p<0.05$ was used to test the statistical significance of all experimental data. All the statistical analyses were achieved using the Graph Pad Prism 8 software (San Diego, CA, USA) and XLSTAT (Addinsoft, New York, NY, USA).

\section{Results}

\subsection{Essential Oil Content and GC-MC Analysis}

The yield of TV-EO was determined on the basis of dry weight. Our results showed that Thymus vulgaris was rich in EO with a yield of about $3.12 \pm 0.14 \%$. Additionally, the chemical composition performed by GC-MS identified 16 different components, representing $91.56 \%$ of the total composition of TV-EO (Table 2). Thymol (38.677\%), p-cymene $(15.66 \%)$, carvacrol $(14.889 \%)$, and $\gamma$-terpinene $(13.308 \%)$ were the most represented. Moreover, this study showed that TV-EO was rich in oxygenated monoterpenes $(54.944 \%)$ and monoterpenes hydrocarbons (33.355\%).

\subsection{Antioxidant Activity}

TV-EO showed a good antioxidant power represented by an $\mathrm{IC}_{50}$ of $0.29 \pm 0.04 \mathrm{mg} / \mathrm{mL}$, $\mathrm{EC}_{50}$ of $0.74 \pm 0.08 \mathrm{mg} / \mathrm{mL}$, and $\mathrm{RC}_{50}$ of $0.59 \pm 0.06 \mathrm{mg} / \mathrm{mL}$ (Table 3). These results were compared with those of the standards, such as ascorbic acid ( $\mathrm{IC}_{50}=0.031 \pm 0.001 \mathrm{mg} / \mathrm{mL}$, and $\left.\mathrm{EC}_{50}=0.095 \pm 0.002 \mathrm{mg} / \mathrm{mL}\right)$, quercetin $\left(\mathrm{IC}_{50}=0.012 \pm 0.002 \mathrm{mg} / \mathrm{mL}, \mathrm{EC}_{50}=\right.$ $0.019 \pm 0.003 \mathrm{mg} / \mathrm{mL}$, and $\left.\mathrm{RC}_{50}=0.052 \pm 0.007 \mathrm{mg} / \mathrm{mL}\right)$, and butylated hydroxytoluene (BHT) $\left(\mathrm{RC}_{50}=0.063 \pm 0.004 \mathrm{mg} / \mathrm{mL}\right)$. 
Table 2. Chemical composition of Thymus vulgaris essential oils (TV-EO).

\begin{tabular}{|c|c|c|c|c|c|c|}
\hline $\mathbf{N}^{\circ}$ & Component & $\mathbf{R I}_{\text {obs }}$ & $\mathrm{RI}_{\text {lit }}$ & Formula & $\begin{array}{c}\text { Method of } \\
\text { Identification }\end{array}$ & $\begin{array}{l}\text { Concentration } \\
\text { (Peak Area \%) }\end{array}$ \\
\hline 1 & $\alpha$-Pinene & 941 & 933 & $\mathrm{C}_{10} \mathrm{H}_{16}$ & RI, MSL & 0.659 \\
\hline 2 & Camphene & 952 & 953 & $\mathrm{C}_{10} \mathrm{H}_{16}$ & RI, MSL & 0.318 \\
\hline 3 & $\beta$-Pinene & 982 & 978 & $\mathrm{C}_{10} \mathrm{H}_{16}$ & RI, MSL & 0.060 \\
\hline 4 & 3-Carene & 1012 & 1009 & $\mathrm{C}_{10} \mathrm{H}_{16}$ & RI, MSL & 2.180 \\
\hline 5 & $\beta$-Phellandrene & 1032 & 1023 & $\mathrm{C}_{10} \mathrm{H}_{16}$ & RI, MSL & 0.080 \\
\hline 6 & O-Cymene & 1024 & 1024 & $\mathrm{C}_{10} \mathrm{H}_{14}$ & RI, MSL & 0.073 \\
\hline 7 & $p$-Cymene & 1025 & 1025 & $\mathrm{C}_{10} \mathrm{H}_{14}$ & RI, MSL & 15.660 \\
\hline 8 & Limonene & 1029 & 1030 & $\mathrm{C}_{10} \mathrm{H}_{16}$ & RI, MSL & 0.528 \\
\hline 9 & $\gamma$-Terpinene & 1058 & 1058 & $\mathrm{C}_{10} \mathrm{H}_{16}$ & RI, MSL & 13.308 \\
\hline 10 & cis-Sabinene hydrate & 1066 & 1069 & $\mathrm{C}_{10} \mathrm{H}_{18}$ & RI, MSL & 0.489 \\
\hline 11 & Borneol & 1169 & 1173 & $\mathrm{C}_{10} \mathrm{H}_{18} \mathrm{O}$ & RI, MSL & 0.721 \\
\hline 12 & $\alpha$-Terpineol & 1193 & 1195 & $\mathrm{C}_{10} \mathrm{H}_{18} \mathrm{O}$ & RI, MSL & 0.657 \\
\hline 13 & Thymol & 1302 & 1293 & $\mathrm{C}_{10} \mathrm{H}_{14} \mathrm{O}$ & RI, MSL & 38.677 \\
\hline 14 & Carvacrol & 1310 & 1300 & $\mathrm{C}_{10} \mathrm{H}_{14} \mathrm{O}$ & RI, MSL & 14.889 \\
\hline 15 & $\beta$-Caryophyllene & 1426 & 1424 & $\mathrm{C}_{15} \mathrm{H}_{24}$ & RI, MSL & 2.728 \\
\hline \multirow[t]{6}{*}{16} & Caryophyllene oxide & 1575 & 1587 & $\mathrm{C}_{15} \mathrm{H}_{24} \mathrm{O}$ & RI, MSL & 0.538 \\
\hline & \multicolumn{5}{|c|}{ Total identified (\%) } & 91.565 \\
\hline & \multicolumn{5}{|c|}{ Monoterpene hydrocarbons } & 33.355 \\
\hline & \multicolumn{5}{|c|}{ Sesquiterpene hydrocarbons } & 2.728 \\
\hline & \multicolumn{5}{|c|}{ Oxygenated monoterpenes } & 54.944 \\
\hline & \multicolumn{5}{|c|}{ Oxygenated sesquiterpenes } & 0.538 \\
\hline
\end{tabular}

$\mathrm{RI}_{\mathrm{obs}}$ : retention index observed in this study; $\mathrm{RI}_{\mathrm{lit}}$ : retention index taken from the literature; MSL: Mass Spectral Library.

Table 3. Antioxidant activity of TV-EO.

\begin{tabular}{lcccc}
\hline & Ascorbic Acid & Quercetin & BHT & TV-EO \\
\hline $\mathrm{IC}_{50}(\mathrm{mg} / \mathrm{mL})$ & $0.031 \pm 0.001^{\mathrm{A}}$ & $0.012 \pm 0.002^{\mathrm{B}}$ & - & $0.29 \pm 0.04^{\mathrm{C}}$ \\
$\mathrm{EC}_{50}(\mathrm{mg} / \mathrm{mL})$ & $0.095 \pm 0.002^{\mathrm{A}}$ & $0.019 \pm 0.003^{\mathrm{B}}$ & - & $0.74 \pm 0.08^{\mathrm{C}}$ \\
$\mathrm{RC}_{50}(\mathrm{mg} / \mathrm{mL})$ & - & $0.052 \pm 0.007^{\mathrm{A}}$ & $0.063 \pm 0.004^{\mathrm{A}}$ & $0.59 \pm 0.06^{\mathrm{C}}$
\end{tabular}

Results are expressed in $\mathrm{mg} / \mathrm{mL}$. Different letters in the same row represent significant differences. (-): not tested.

\subsection{Antimicrobial Activity}

3.3.1. Disc Diffusion Method, MIC, MBC, and Percentage of Sublethal-Injured Cells

The results obtained for the disc diffusion assay showed that all the Salmonella strains tested were susceptible to the TV-EO activity. For all the tested strains, the antimicrobial activity of TV-EO was considered strong since the diameters of inhibition were $\geq 20.1 \mathrm{~mm}$; in particular, between $24 \pm 0.4 \mathrm{~mm}$ and $32 \pm 0.6 \mathrm{~mm}$ (Figure 1). Despite the zones of inhibition determined by the TV-EO were larger than those determined by the reference antibiotic (CTX), only for S1 and S2, strains there were of significant difference $(p<0.05)$ related to the resistance at the reference test; not significant differences were observed among the susceptibility of the strains to the TV-EO $(p>0.05)$. 


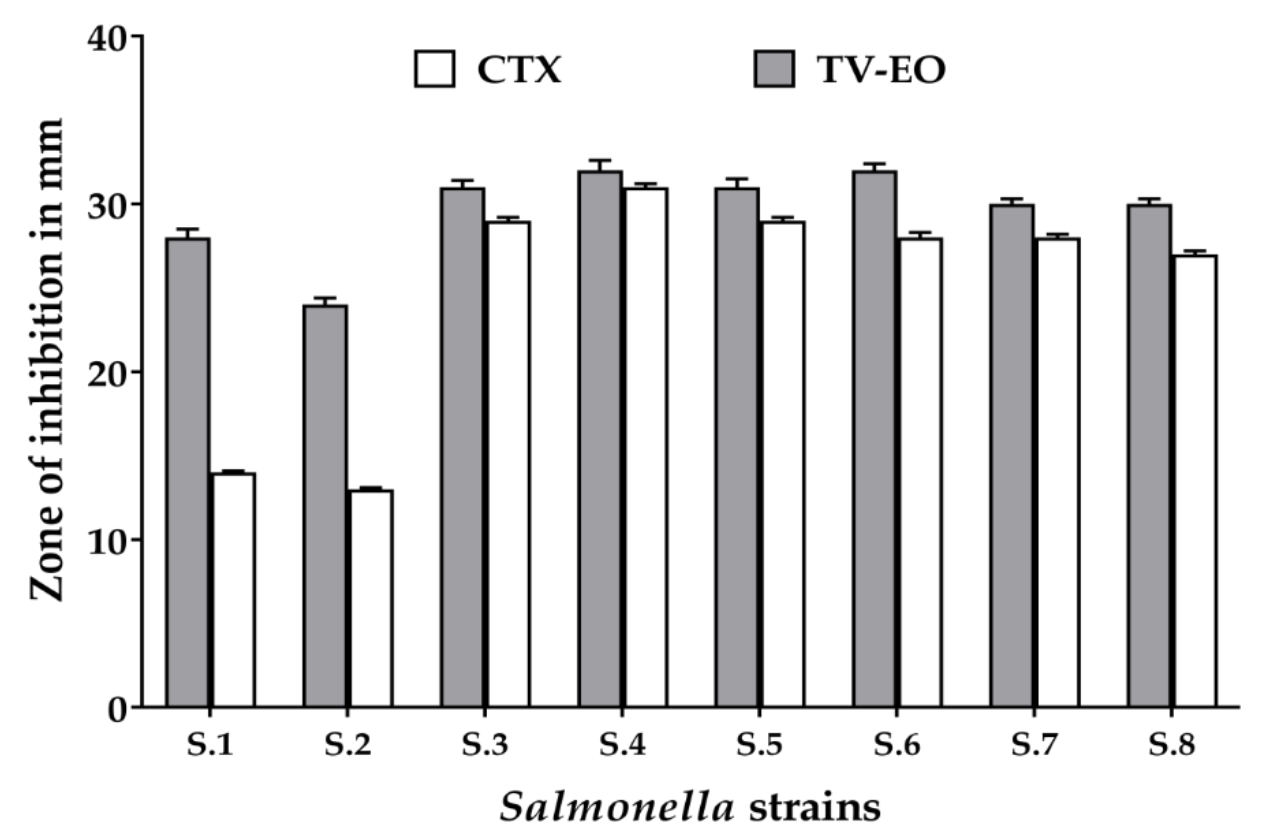

Figure 1. Inhibition diameters $(\mathrm{mm})$ of the tested EOs against the eight different strains of Salmonella enteritidis. CTX $=$ Cefotaxime $(30 \mu \mathrm{g})$ as reference test; TV-EO $=$ Thymus vulgaris essential oil $(10 \mu \mathrm{L})$.

The results obtained by the microdilution assay confirmed the performing antimicrobial activity of the TV-EO observed in the agar disk diffusion test. In detail, all the tested strains showed the same susceptibility to TV-EO that had a MIC of $0.5 \%$ and an MBC of $1 \%$ (Table 4).

Table 4. Minimum inhibitory concentration (MIC) and minimum bactericidal concentration (MBC) in percentage $(\mathrm{v} / \mathrm{v})$ of TV-EO against Salmonella and percentage of sublethal-injured cell after exposition to TV-EO.

\begin{tabular}{|c|c|c|c|c|c|c|}
\hline & \multicolumn{2}{|c|}{ \% Sublethal-Injured Cell } & \multirow{2}{*}{ ID Strain } & \multirow{2}{*}{ MIC } & \multirow{2}{*}{ MBC } & \multirow{2}{*}{$\mathbf{r}$} \\
\hline & Control & TV-EO & & & & \\
\hline \multirow{8}{*}{ Salmonella } & \multirow{8}{*}{$3.72 \pm 0.04$} & \multirow{8}{*}{$7.99 \pm 0.08$} & S1 & $0.5 \%$ & $1 \%$ & 2 \\
\hline & & & S2 & $0.5 \%$ & $1 \%$ & 2 \\
\hline & & & S3 & $0.5 \%$ & $1 \%$ & 2 \\
\hline & & & S4 & $0.5 \%$ & $1 \%$ & 2 \\
\hline & & & S5 & $0.5 \%$ & $1 \%$ & 2 \\
\hline & & & S6 & $0.5 \%$ & $1 \%$ & 2 \\
\hline & & & S7 & $0.5 \%$ & $1 \%$ & 2 \\
\hline & & & S8 & $0.5 \%$ & $1 \%$ & 2 \\
\hline
\end{tabular}

r: ratio MBC/MIC.

Considering that the MIC and MBC were the same for all the tested strains, the percentages of sublethal-injured cells caused by TV-EO were established for only one Salmonella strain, and the results obtained are presented in Table 4. Our findings showed that TV-EO at the half-MIC concentration $(0.25 \%)$ resulted in sublethal damage to Salmonella, which was more susceptible to the well-known bacteriostatic activity of salt [47]. In this regard, the percentage of sublethal-injured Salmonella was $7.99 \pm 0.08 \%$, definitely higher than those observed in the control samples of $3.72 \pm 0.04 \%$. 


\subsubsection{In Vitro Effect of TV-EO on the Growth of Salmonella}

The obtained results showed that TV-EO inhibited the growth of Salmonella at all the tested concentrations (Figure 2). However, the antibacterial efficiency was significant only for the highest concentrations. In fact, the observed growth curves for $0.25 \%$ TV-EO were stackable to those observed for the control samples at both storage temperatures. On the other hand, the $0.4 \%$ and $0.5 \%$ TV-EO efficiently slowed the growth rate at both storage temperatures. When at $10{ }^{\circ} \mathrm{C}$, the control samples reached the stationary phase $(8.53 \pm 0.37 \mathrm{Log} \mathrm{CFU} / \mathrm{g})$ after $144 \mathrm{~h}$, the load of samples treated with $0.4 \%$ TV-EO was more than $2 \log$ lower $(6.38 \pm 0.37 \mathrm{Log}$ CFU $/ g)$. The $0.5 \%$ TV-EO even led to complete inhibition of growth already after $48 \mathrm{~h}$ at $10^{\circ} \mathrm{C}$. The antimicrobial effect was also confirmed by the results obtained at $20^{\circ} \mathrm{C}$. In fact, loads of $9 \pm 0.39 \mathrm{Log} \mathrm{CFU} / \mathrm{g}$ were counted after $52 \mathrm{~h}$ in the control samples, while for samples treated with $0.4 \%$ and $0.5 \%$ TV-EO, lower loads of $8.15 \pm 0.43$ and $7.61 \pm 0.44$ were counted, respectively.
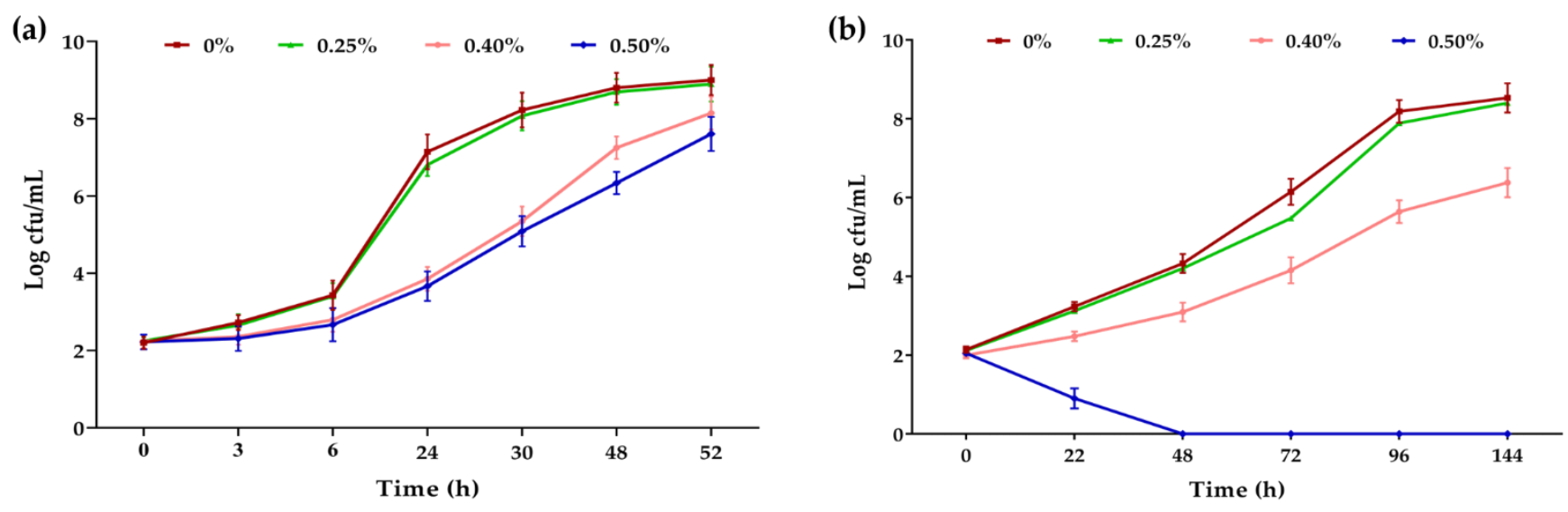

Figure 2. The in vitro effect of TV-EO $(v / v)$ on the growth of Salmonella at $20^{\circ} \mathrm{C}(\mathbf{a})$ and $10{ }^{\circ} \mathrm{C}(\mathbf{b})$.

\subsection{Predictive Model}

The values obtained for $\xi, N_{\max }$, and $Q_{0}$ for each TV-EO concentration are reported in Table 5. Figures 3 and 4 show the predicted data obtained resolving Equations (3) and (4) with the specific $\xi$ values. As observed in Table 5 and Figures 3 and 4, the proposed model allowed to obtain a good fitting with the data of Salmonella growth obtained in the in vitro treatments, with the different concentrations of TV-EO. The goodness of the predictive approach derived from the proposed model was confirmed by the good fitting observed for the growth curve of the untreated samples of Salmonella.

Table 5. Primary parameters for each predicted curve.

\begin{tabular}{ccccccccc}
\hline \multicolumn{1}{c}{$2{ }^{\circ} \mathbf{C}$} & \multicolumn{5}{c}{$1{ }^{\circ} \mathbf{C}$} \\
\hline$\%$ TV-EO & $0 \%$ & $0.5 \%$ & $0.4 \%$ & $0.25 \%$ & $0 \%$ & $0.5 \%$ & $0.4 \%$ & $0.25 \%$ \\
$\xi$ values & 1 & 0.4 & 0.55 & 0.7 & 1 & -2.5 & 0.85 & 0.95 \\
$\mathrm{Q}_{0}$ & 0.5 & 0.03 & 0.03 & 0.5 & 0.7 & 0.7 & 0.7 & 0.7 \\
$\mathrm{~N}_{\max }$ & 8.6 & 8.6 & 8.6 & 8.6 & 10.6 & 10.6 & 10.6 & 10.6 \\
\hline
\end{tabular}



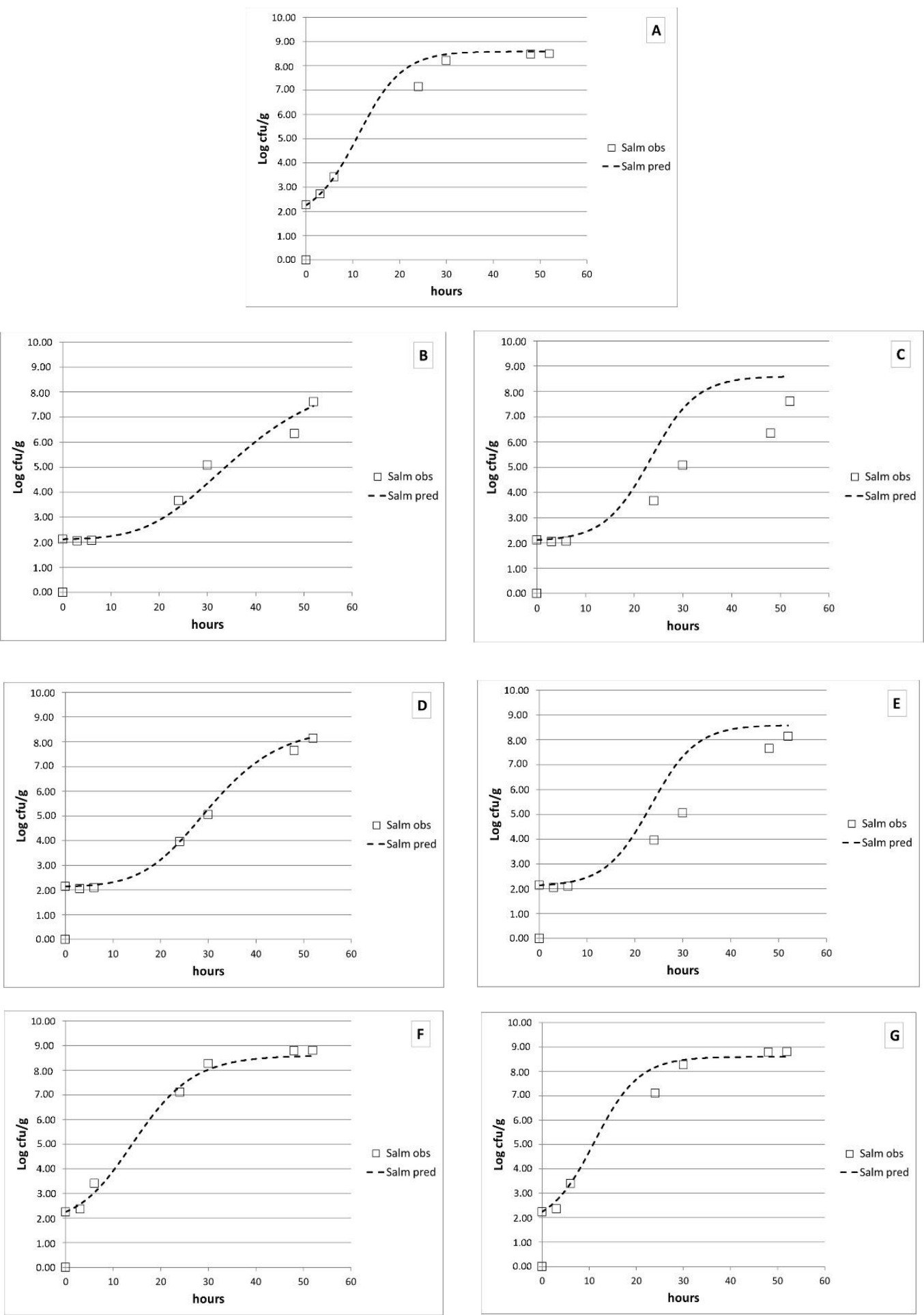

Figure 3. Predicted (dotted line) and observed (squares) growth curves of Salmonella at $20{ }^{\circ} \mathrm{C}$. Panel (A): control series; panel (B): 0.5\% TV-EO and $\xi=-2.5$; panel (C): 0.5\% TV-EO and $\xi=0.0$; panel (D): 0.4\% TV-EO and $\xi=0.85$; panel (E): 0.4\% TV-EO and $\xi=0.00$; panel (F): 0.25\% TV-EO and $\xi=0.9$; panel (G): 0.25\% TV-EO and $\xi=0.0$. 

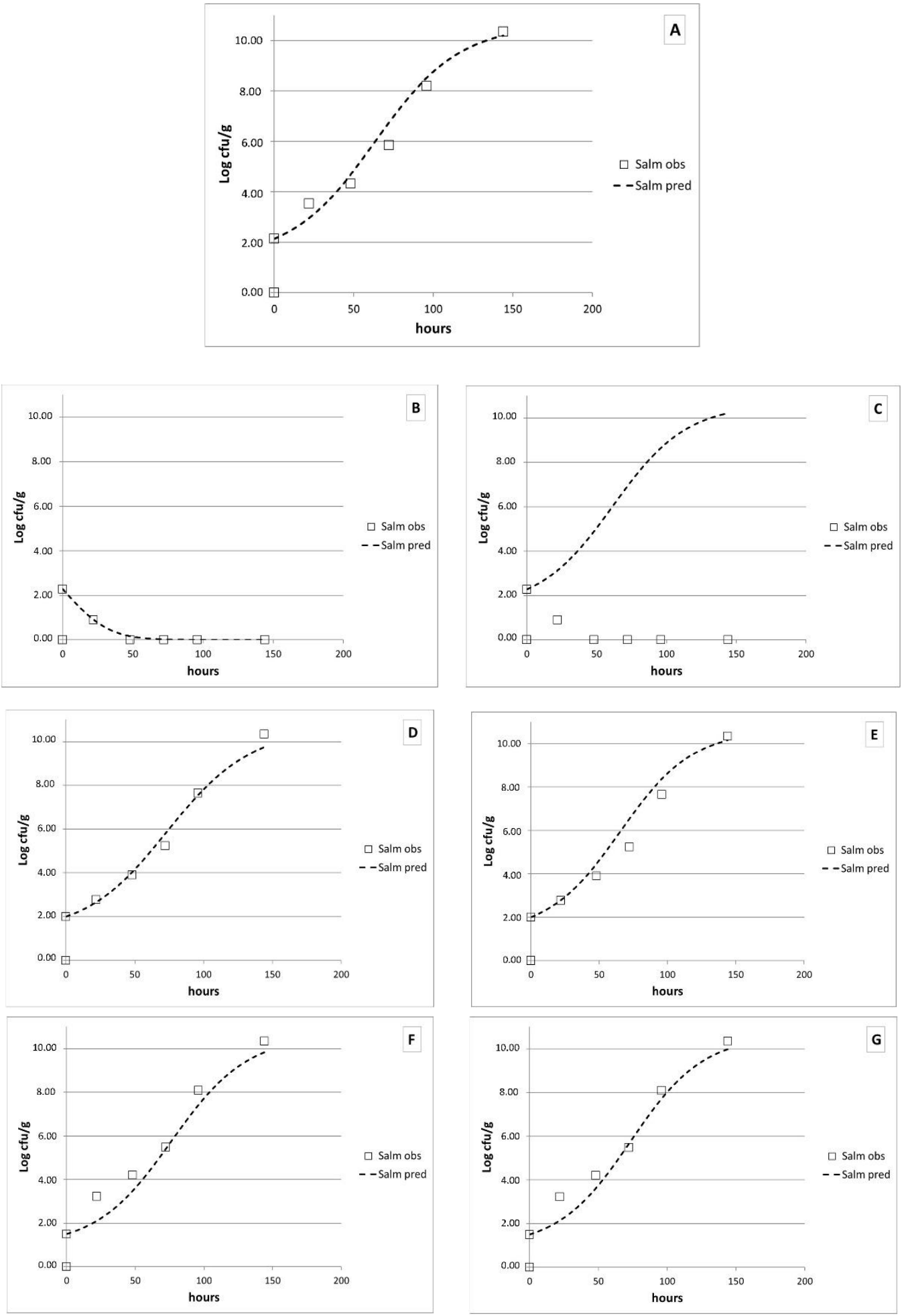

Figure 4. Predicted (dotted line) and observed (squares) growth curves of Salmonella at $10{ }^{\circ} \mathrm{C}$. Panel (A): control series; panel (B): 0.5\% TV-EO and $\xi=0.4 ;$ panel (C): 0.5\% TV-EO and $\xi=0.0$; panel (D): $0.4 \%$ TV-EO and $\xi=0.55$; panel (E): $0.4 \%$ TVEO and $\xi=0.00$; panel (F): $0.25 \%$ TV-EO and $\xi=0.7$; panel (G): $0.25 \%$ TV-EO and $\xi=0.0$.

The linear regression observed at $20^{\circ} \mathrm{C}$ (Figure 5A) showed a linear relationship between the $\xi$ values and the percentage of TV-EO, whereas the data obtained at $10^{\circ} \mathrm{C}$ (Figure 5B) were not linearly related to the TV-EO concentration. 

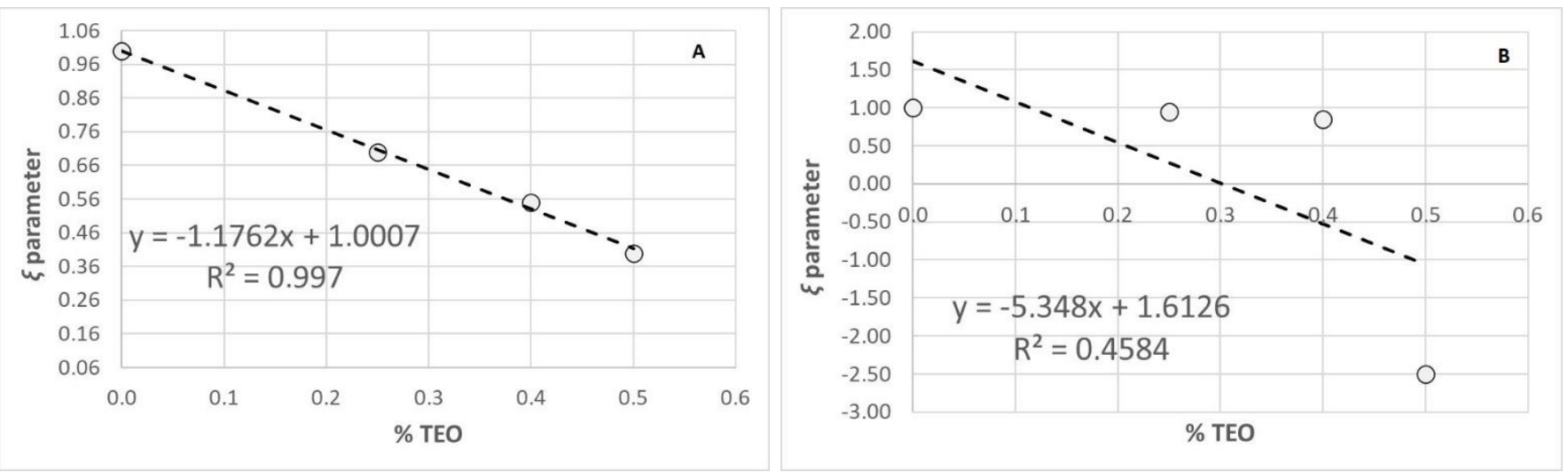

Figure 5. Panel (A): Linear regression of $\xi$ values against the percentage of TV-EO of each trial at $20{ }^{\circ} \mathrm{C}$. Panel (B): linear regression of $\xi$ values against the percentage of TV-EO of each trial at $10{ }^{\circ} \mathrm{C}$.

The results obtained for $\xi$ parameter by the calculation of RMSE are reported in Table 6; the introduction of the $\xi$ parameter was specific for each TV-EO concentration and reproduced the antibacterial effect regardless of the prediction of growth rate; therefore, it was not introduced into the secondary model. The numerical parametrization of $\xi$ was easily obtained with a simple fitting procedure and allowed to find a set of $\xi$ values concentration-dependent.

Table 6. The root-mean-squared error (RMSE) for each prediction.

\begin{tabular}{|c|c|c|c|c|}
\hline & \multicolumn{2}{|c|}{$20{ }^{\circ} \mathrm{C}$} & \multicolumn{2}{|c|}{$10^{\circ} \mathrm{C}$} \\
\hline & $\xi$ Included & $\xi$ Not Included & $\xi$ Included & $\xi$ Not Included \\
\hline $0.50 \%$ TV-EO & 0.4089 & 1.4310 & 0.0683 & 6.5311 \\
\hline $0.40 \%$ TV-EO & 0.1615 & 1.1290 & 0.3421 & 0.6519 \\
\hline $0.25 \%$ TV-EO & 0.2385 & 0.4418 & 0.6474 & 0.5521 \\
\hline
\end{tabular}

\subsection{Antimicrobial Activity in Poultry Minced Meat}

The results obtained for the in situ antimicrobial activity of TV-EO in poultry minced meat were presented in Table 7 . The 1\% TV-EO showed the highest efficiency against Salmonella growth, which was completely inhibited after 3 days of storage. The effectiveness of $1 \%$ TV-EO was corroborated by the counts of the Enterobacteriaceae, which decreased significantly after one day of treatment and then remained constant until after 13 days. The $0.5 \%$ TV-EO also showed antimicrobial activity against Salmonella, while no significant effect was observed against Enterobacteriaceae. In this regard, despite no substantial differences were observed until the 6th day of storage compared to the CTX samples, Salmonella growth was significantly inhibited already starting from the 9th day and then completely inhibited on the 13th day of treatment. Nevertheless, no significant antimicrobial effects were observed against Salmonella and Enterobacteriaceae for the $0.25 \%$ and $0.125 \%$ TV-EO, comparing the results of the control samples. 
Table 7. Variation rate of Salmonella and Enterobacteriaceae during the storage of poultry minced meat treated with different concentrations of TV-EO.

\begin{tabular}{|c|c|c|c|c|c|c|}
\hline \multirow{2}{*}{ Bacteria } & \multirow{2}{*}{$\begin{array}{l}\text { Time } \\
\text { (Days) }\end{array}$} & \multicolumn{5}{|c|}{ Concentrations of TV-EO } \\
\hline & & $0 \%$ (Control) & $0.125 \%$ & $0.25 \%$ & $0.5 \%$ & $1 \%$ \\
\hline \multirow{6}{*}{ Salmonella } & 0 & $3.150 \pm 0.0065^{\mathrm{A}}$ & $3.150 \pm 0.0065^{\mathrm{A}}$ & $3.151 \pm 0.0065^{\mathrm{A}}$ & $3.151 \pm 0.0065^{\mathrm{A}}$ & $3.151 \pm 0.0065^{\mathrm{A}}$ \\
\hline & 1 & $3.015 \pm 0.100 \mathrm{~A}$ & $3.067 \pm 0.0368^{\mathrm{A}}$ & $2.933 \pm 0.0429^{A}$ & $2.951 \pm 0.0685^{\mathrm{A}}$ & $0.92 \pm 0.1651^{C}$ \\
\hline & 3 & $3.075 \pm 0.0362^{\mathrm{A}}$ & $3.037 \pm 0.0169 \mathrm{~A}$ & $2.841 \pm 0.0883^{\mathrm{A}}$ & $2.806 \pm 0.0192 \mathrm{~A}$ & $0.000 \pm 0.000^{\mathrm{B}}$ \\
\hline & 6 & $2.963 \pm 0.0267^{\mathrm{A}}$ & $2.923 \pm 0.0439 \mathrm{~A}$ & $2.648 \pm 0.0963^{\mathrm{A}}$ & $2.612 \pm 0.0450^{\mathrm{A}}$ & $0.000 \pm 0.000^{\mathrm{B}}$ \\
\hline & 9 & - & - & - & $0.500 \pm 0.1707^{\mathrm{B}}$ & $0.000 \pm 0.000^{\mathrm{B}}$ \\
\hline & 13 & - & - & - & $0.000 \pm 0.000^{\mathrm{B}}$ & $0.000 \pm 0.000^{\mathrm{B}}$ \\
\hline \multirow{6}{*}{ Enterobacteriaceae } & 0 & $4.276 \pm 0.0032^{\mathrm{D}}$ & $4.276 \pm 0.0032^{\mathrm{D}}$ & $4.276 \pm 0.0032^{\mathrm{D}}$ & $4.276 \pm 0.0032^{\mathrm{D}}$ & $4.276 \pm 0.0032^{\mathrm{D}}$ \\
\hline & 1 & $4.430 \pm 0.0455^{\mathrm{D}}$ & $4.576 \pm 0.0154^{\mathrm{D}}$ & $4.475 \pm 0.0625^{\mathrm{D}}$ & $3.782 \pm 0.0708^{\mathrm{D}}$ & $2.539 \pm 0.3373^{G}$ \\
\hline & 3 & $5.346 \pm 0.1386^{\mathrm{E}}$ & $4.979 \pm 0.0354^{\mathrm{D}}$ & $4.878 \pm 0.0649^{\mathrm{D}}$ & $4.396 \pm 0.0123^{\mathrm{D}}$ & $2.522 \pm 0.1283^{G}$ \\
\hline & 6 & $6.555 \pm 0.1079^{\mathrm{F}}$ & $6.374 \pm 0.0977^{\mathrm{F}}$ & $5.972 \pm 0.1298^{\mathrm{EF}}$ & $5.481 \pm 0.0708^{\mathrm{E}}$ & $2.50 \pm 0.067^{\mathrm{G}}$ \\
\hline & 9 & - & - & - & $6.212 \pm 0.0433^{\mathrm{F}}$ & $2.00 \pm 0.2814^{G}$ \\
\hline & 13 & - & - & - & $6.539 \pm 0.2003^{F}$ & $1.739 \pm 0.445^{G}$ \\
\hline
\end{tabular}

(-): not calculated. Different letters stand for statistically significant differences at $p<0.05$ according to Fisher's least significant difference (LSD) test.

\subsection{Sensorial Analysis}

The results obtained for the sensory analysis are presented in Table 8. On day 0 , the flavor, color, and taste of the minced samples achieved the highest score for all tested TV-EO concentrations. During storage, the sensory properties of the mince decreased following the bacterial growth and oxidation processes. However, the acceptability limit of the samples treated with TV-EO was higher than that of the control samples for all tested concentrations. The decay of color and taste proceeded significantly slower in the samples treated with different concentrations of TV-EO than in the control ones. Less significant differences were observed for the flavor, although, in no analysis interval the score of the treated samples lower than that of the control ones for all concentrations tested. At the end of the experiment, the color, flavor, and taste were still acceptable in the mince samples treated with $1 \%$ and $0.5 \%$ of TV-EO after 13 days. Instead, odor, color, and taste scores of minces treated with $0.25 \%$ and $0.125 \%$ of TV-EO reached the limit of acceptability on the 6th day. After cooking, the flavor of the mice was more acceptable (data are not shown). The $1 \%$ of TV-EO influenced the typical taste of the treated mince samples, even if it was not considered unpleasant by any of the panelists. A lower influence on the typical taste of the mince was perceived by the panelists for those samples treated with $0.5 \%$ of TV-EO.

Table 8. Average grade of sensory analysis of poultry minced meat treated with different concentrations of TV-EO.

\begin{tabular}{|c|c|c|c|c|c|c|}
\hline \multirow{2}{*}{ Parameters } & \multirow{2}{*}{$\begin{array}{l}\text { Time } \\
\text { (Days) }\end{array}$} & \multicolumn{5}{|c|}{ Concentrations of TV-EO } \\
\hline & & $0 \%$ (Control) & $0.125 \%$ & $0.25 \%$ & $0.5 \%$ & $1 \%$ \\
\hline \multirow{6}{*}{ Color } & 0 & $10 \pm 0.000^{\mathrm{L}}$ & $10 \pm 0.000^{\mathrm{L}}$ & $10 \pm 0.000^{\mathrm{L}}$ & $10 \pm 0.000^{\mathrm{L}}$ & $10 \pm 0.000^{\mathrm{L}}$ \\
\hline & 1 & $8.25 \pm 0.353^{\mathrm{IJ}}$ & $9 \pm 0.707^{\mathrm{K}}$ & $9 \pm 0.707^{\mathrm{K}}$ & $9 \pm 0.000^{\mathrm{K}}$ & $9 \pm 0.000^{K}$ \\
\hline & 3 & $6.25 \pm 0.353^{\mathrm{DE}}$ & $7.5 \pm 0.707^{\mathrm{GH}}$ & $8 \pm 000^{\mathrm{HI}}$ & $8.75 \pm 0.353^{\mathrm{JK}}$ & $8.75 \pm 0.353 \mathrm{JK}$ \\
\hline & 6 & $4.25 \pm 0.353^{\mathrm{A}}$ & $5.25 \pm 0.353^{B C}$ & $5 \pm 0.000^{\mathrm{B}}$ & $8 \pm 0.00^{\mathrm{HI}}$ & $8.25 \pm 0.353^{\mathrm{IJ}}$ \\
\hline & 9 & - & - & - & $6.75 \pm 0.353^{\mathrm{EF}}$ & $7.25 \pm 0.353^{\mathrm{FG}}$ \\
\hline & 13 & - & - & - & $5.5 \pm 0.00^{\mathrm{BC}}$ & $5.75 \pm 0.353 \mathrm{CD}$ \\
\hline \multirow{6}{*}{ Flavor } & 0 & $10 \pm 0.000 \mathrm{~J}$ & $10 \pm 0.000 \mathrm{~J}$ & $10 \pm 0.000 \mathrm{~J}$ & $10 \pm 0.000 \mathrm{~J}$ & $10 \pm 0.000 \mathrm{~J}$ \\
\hline & 1 & $8 \pm 0.00^{\mathrm{F}}$ & $8.25 \pm 0.353^{\mathrm{FG}}$ & $8.5 \pm 0.353^{\mathrm{GH}}$ & $8.75 \pm 0.000^{\mathrm{HI}}$ & $9.75 \pm 0.353^{J}$ \\
\hline & 3 & $6.75 \pm 0.353^{\mathrm{D}}$ & $6.75 \pm 0.353^{\mathrm{D}}$ & $6.75 \pm 0.353^{\mathrm{D}}$ & $8 \pm 0.000^{\mathrm{F}}$ & $9 \pm 0.000^{\mathrm{I}}$ \\
\hline & 6 & $4.25 \pm 0.353^{\mathrm{A}}$ & $5 \pm 0.00^{\mathrm{B}}$ & $5.25 \pm 0.353^{B}$ & $7.25 \pm 0.353^{\mathrm{E}}$ & $8.25 \pm 0.353^{\mathrm{FG}}$ \\
\hline & 9 & - & - & - & $6.75 \pm 0.353^{\mathrm{D}}$ & $7.25 \pm 0.353^{\mathrm{E}}$ \\
\hline & 13 & - & - & - & $5.25 \pm 0.353^{B}$ & $6 \pm 0.000^{C}$ \\
\hline
\end{tabular}


Table 8. Cont.

\begin{tabular}{ccccccc}
\hline \multirow{2}{*}{$\begin{array}{c}\text { Parameters } \\
\text { Time }\end{array}$} & \multicolumn{5}{c}{ Concentrations of TV-EO } \\
\cline { 3 - 7 } & (Days) & $\mathbf{0 \% \text { (Control) }}$ & $\mathbf{0 . 1 2 5 \%}$ & $\mathbf{0 . 2 5 \%}$ & $\mathbf{0 . 5 \%}$ & $\mathbf{1 \%}$ \\
\hline \multirow{2}{*}{ Taste } & 0 & $10 \pm 0.000^{\mathrm{M}}$ & $10 \pm 0.000^{\mathrm{M}}$ & $10 \pm 0.000^{\mathrm{M}}$ & $10 \pm 0.000^{\mathrm{M}}$ & $10 \pm 0.000^{\mathrm{M}}$ \\
& 1 & $8.017 \pm 0.206^{\mathrm{V}}$ & $8.326 \pm 0.553^{\mathrm{V}}$ & $9.052 \pm 0.051^{\mathrm{W}}$ & $8.706 \pm 0.124^{\mathrm{W}}$ & $9.543 \pm 0.395^{\mathrm{M}}$ \\
& 3 & $6.331 \pm 0.332^{\mathrm{E}}$ & $7.077 \pm 0.329^{\mathrm{Y}}$ & $7.128 \pm 0.176^{\mathrm{Y}}$ & $8.121 \pm 0.164^{\mathrm{V}}$ & $8.723 \pm 0.254^{\mathrm{W}}$ \\
& 6 & $4.664 \pm 0.487^{\mathrm{N}}$ & $5.864 \pm 0.116^{\mathrm{O}}$ & $5.3 \pm 0.511^{\mathrm{O}}$ & $7.293 \pm 0.156^{\mathrm{Y}}$ & $8.016 \pm 0.134^{\mathrm{V}}$ \\
& 9 & - & - & - & $6.864 \pm 0.320^{\mathrm{E}}$ & $6.96 \pm 0.053^{\mathrm{EY}}$ \\
& 13 & - & - & - & $5.178 \pm 0.307^{\mathrm{O}}$ & $5.657^{2} \pm 0.493^{\mathrm{O}}$ \\
\hline
\end{tabular}

(-): not calculated. Different letters stand for statistically significant differences at $p<0.05$ according to Fisher's LSD test.

\section{Discussions}

The results of our study showed that TV-EO had an extraction yield of $3.12 \pm 0.14 \%$. These results were higher than those reported for the TV-EO collected from the National Institute of Medicinal and Aromatic Plants in Taounate (Morocco; 1.9\%) [48], those described in TV-EO collected from Barzo Mountain Shirvan (North Khorasan Province of Iran) at different stages of plant growth (0.83-1.39\%) [49], and those collected from Caxias do Sul (Rio Grande do Sul State, Brazil) with a yield of $0.25 \%$ [50]. On the other hand, they were lower than those described previously in the Ash-Shoubak region in the South of Jordan (4.7\%) [50]. These discrepancies are related to different internal and external factors that affected the yield of plant EOs, including physiological variations of plant species, environmental conditions, growth stage, and genetic factors and evolution [51,52]. Therefore, it is not surprising that different chemical compositions for the same EO were reported. The results obtained showed that the TV-EO tested in the present study was rich in thymol (38.677\%), followed by p-cymene (15.66\%), carvacrol $(14.889 \%)$, and $\gamma$-terpinene $(13.308 \%)$. These findings were consistent with those of previous studies that reported the dominance of thymol in TV-EO $[4,15,17,48]$. However, linalool $(76.2 \%)$, geraniol $(59.8 \%)$, and cis-sabinene hydrate $(30.8 \%)$ were identified as the major components of TV-EO collected from France and Serbia [53], and camphor (38.54\%) in TV-EO collected from the eastern regions of Morocco [54].

Oxidation is a chemical reaction that leads to the deterioration of food products and the loss of organoleptic quality [55]. This reaction is under the effect of different factors such as light, oxygen partial pressure, temperature, relative humidity, and lipid oxidation [56]. The inhibition of food oxidation is a great challenge for industrialists and scientists, taking into consideration the increased demand for bio-preservatives and the limited use of chemical substances [55]. The antioxidant activity of EOs corresponds to its capacity to reduce and retard the oxidation of an oxidizable material, even when used in a very modest amount [57]. The results of our study showed that TV-EO had good antioxidant activity and, thanks to the antimicrobial activity, could be used to extend the shelf life of food products and pleasantly influence their sensory characteristics [58]. Our results are comparable to those reported previously in different studies, which classified TV-EO with moderate to high antioxidant power [59-62]. The powerful antioxidant activity of TV-EO, compared to other EOs [13], could be explained by its chemical composition and its richness in thymol and carvacrol. In this regard, Aeschbach and his group showed that thymol and carvacrol had good antioxidant activity and could be used as natural antioxidant compounds [63]. Further, $\gamma$-terpinene showed good antioxidant properties as well when used alone or in synergy with other components [64-66]. Moreover, $\beta$-caryophyllene displayed a strong antioxidant effect and could improve the activity of EOs even at a low concentration [67]. The performing results obtained for the antioxidant activity were also corroborated by the sensory analysis of the in situ experiments. In fact, the color score of the treated samples was higher than in the control ones for all the concentration tested, and at $0.5 \%$ and $1 \%$ the color acceptability limit increased up to 7 days. 
The results of the antibacterial activity showed that TV-EO effectively inhibited the growth of Salmonella. Different mechanisms were proposed to explain the inhibition effect of EOs against bacteria [7,68]. In particular, EOs may determine damage to the bacterial wall by increasing the cell membrane permeability, changing their morphology, and decreasing the ATP synthesis [7]. These effects could increase the effectiveness of other preservative compounds, as demonstrated for the salt during the evaluation of the injured cells treated with a low concentration of TV-EO. The obtained percentage of sublethal-injured cells of Salmonella exposed to TV-EO was higher than those determined by EOs of Origanum majorana, Mentha suaveolens, Rosmarinus officinalis, Salvia officinalis, and Mentha pulegium [13]. The antibacterial activity of TV-EO was related to the high content of thymol and carvacrol, whose antibacterial activity is well known and was reported by several authors [69]. Additionally, the antibacterial activity of p-cymene and $\gamma$-terpinene was demonstrated and could also participate in improving the effectiveness of TV-EO [70]. The observed MIC of $0.5 \%(5 \mathrm{mg} / \mathrm{mL})$ for all the eight tested strains was in accordance with those reported by Bartkiene et al. [71] that ranged from 1\% to $0.1 \%$ on similar Salmonella strains; while the essential oil obtained from the Brazilian thyme plant showed more effectiveness on Salmonella choleraesuis with a MIC of $0.6 \mathrm{mg} / \mathrm{mL}$ [72]. These differences were related to the strong variability in the chemical composition of the EOs and to the different susceptibility of strains [73].

Satisfactory results were obtained with the proposed predictive model that allowed to describe the in vitro Salmonella behavior exposed to TV-EO with confidence. The growth curves predicted for Salmonella well-fitted the results obtained during the in vitro microbiological analysis at both $20{ }^{\circ} \mathrm{C}$ and $10{ }^{\circ} \mathrm{C}$ of exposition. The presence and count of a food pathogen can change during all steps of food processing based on the way the food is handled. The implemented model might be a useful tool for food industries to assess the effects of different storage conditions on the final Salmonella contamination of a product at the time of consumption. Therefore, further studies are needed directly in food matrices, in which more parameters $(\mathrm{pH}$, water activity, presence of nutrients, atmosphere conditions, etc.) must be considered to establish the applicability of the presented model. Results of the regression analysis showed that the antimicrobial effects of the different TV-EO concentrations against Salmonella varied on the basis of temperatures. In detail, linear regression observed at $20{ }^{\circ} \mathrm{C}$ (Figure 5A) showed a linear relationship between the percentage of TV-EO and its antimicrobial activity, whereas no linear correlation was observed from the data obtained at $10^{\circ} \mathrm{C}$ (Figure 5B). This result is probably related to the fact that the antimicrobial activity of essential oils increases at lower storage temperatures due to a greater susceptibility of the bacteria [74].

The results of the in situ antimicrobial activity and sensory evaluation showed that TV-EO could be a suitable natural preservative to manage the Salmonella risk in foods. In this regard, Salmonella growth in experimentally contaminated mince poultry meat was completely inhibited (at $4{ }^{\circ} \mathrm{C}, 3 \mathrm{Log}$ reduction) after 3 days of treatment with $1 \% \mathrm{TV}$ $\mathrm{EO}$, and the sensory properties of the meat were maintained for up to one week longer than in the untreated samples. Our findings were in line with those reported by other authors $[14,44]$. Olaimat et al. reported that the addition of TV-EO at a concentration of $0.5-1.5 \%$ to hummus reduced Salmonella by 1.0-2.9 $\log$ CFU/g after storage of 10 days at $4{ }^{\circ} \mathrm{C}$ [14]. Same, Boskovic et al. reported the reduction of Salmonella in minced pork by 1.69-4.05 log CFU/g after treatment with TV-EO (0.3-0.9\%) packaged under vacuum or $\operatorname{MAP}\left(30 \% \mathrm{O}_{2} ; 50 \% \mathrm{CO}_{2} ; 20 \% \mathrm{~N}_{2}\right)$ and storage at $3 \pm 1{ }^{\circ} \mathrm{C}$ for 15 days [44]. The antimicrobial effect against Salmonella herein reported for TV-EO was also comparable to that observed for other EOs such as sage, basil, and rosemary tested in chicken meat $[75,76]$. The literature published so far pointed out that the use of thyme in foods was almost exclusively limited to meat products [77], although its effects were also studied on fish [78] and cheese [79]. The main goal of using thyme in foods was to extend their shelf-life. In this regard, several studies reported that the $\mathrm{EO}$ of thyme delayed the rancidity development of fat and inhibited the growth of spoilage microorganisms in different types of foods [61,77]. 
These latter considerations may underlie the slower decay of sensory properties (color, odor, and taste) observed in the present study for the minced poultry meat treated with TV-EO at $0.5 \%$ and $1 \%$. However, the main limiting factor of the use of TV-EO was related to its influences on the typical organoleptic properties of foods. Although thyme is widely used as a food condiment, it is important that its use did not excessively mask the sensory characteristics of the product, making it unpleasant to the consumer. In this regard, despite the sensory influence, $1 \%$ TV-EO was not considered unpleasant by any of the panelists, $0.5 \%$ TV-EO was considered the best compromise to extend the sensory acceptability of the meat without significantly influencing its typical taste. Interestingly, the results of our study showed that, after cooking, the flavor and taste of the minced poultry meat were more acceptable. In this regard, we might speculate that the high temperature influenced the stability of the volatile compounds of the TV-EO, which were partly mixed with meat aromas as previously reported by Boskovic et al. [80] and Van Haute et al. [81], resulting in a pleasant flavor and taste.

\section{Conclusions}

The results of this study showed that thymol and p-cymene were the main constituents of the EO of Thymus vulgaris collected from the mountainous region of Ifrane (Morocco) and principally responsible for its beneficial effects. TV-EO revealed a good antioxidant activity as well as relevant antibacterial effects against all the Salmonella strains tested. Determination of the percentage of sublethal-injured cells showed that TV-EO could be used in synergy with other compounds like salt to improve their effects. Furthermore, TV-EO overcame the limits related to the organoleptic influences on foods which were appreciated during the sensory analysis. This study confirmed that TV-EO could be considered a suitable natural alternative to ensure food safety and quality according to the new green trends in the food field for more natural, healthy, and low environmental impact foodstuffs.

Author Contributions: Conceptualization, F.G., A.G., and F.R.F.; methodology, F.G., A.G., and F.R.F.; software, A.G., Y.O.E.M., L.N., and B.B.; validation, A.G. and B.B.; formal analysis, L.N., N.T., A.E.-D., and Y.O.E.M.; investigation, A.E.-D., L.N., and N.T.; data curation, A.E.-D., L.N., A.G., and F.G.; writing—original draft preparation, L.N. and A.E.-D.; writing—review \& editing, L.N., A.E.-D., A.G., and F.G.; supervision, F.G. All authors have read and agreed to the published version of the manuscript.

Funding: This research received no external funding.

Institutional Review Board Statement: Not applicable.

Informed Consent Statement: Informed consent was obtained from all subjects involved in the study.

Data Availability Statement: Not applicable.

Acknowledgments: The authors are grateful to the anonymous reviewers for their valuable comments and suggestions.

Conflicts of Interest: The authors declare no conflict of interest.

\section{References}

1. Cassman, K.G.; Grassini, P. A global perspective on sustainable intensification research. Nat. Sustain. 2020, 3, 262-268. [CrossRef]

2. Del Nobile, M.A.; Lucera, A.; Costa, C.; Conte, A. Food applications of natural antimicrobial compounds. Front. Microbiol. 2012, 3, 287. [CrossRef]

3. Trabelsi, N.; Nalbone, L.; Marotta, S.M.; Taamali, A.; Abaza, L.; Giarratana, F. Effectiveness of five flavored Tunisian olive oils on Anisakis larvae type 1: Application of cinnamon and rosemary oil in industrial anchovy marinating process. J. Sci. Food Agric. 2019, 99, 4808-4815. [CrossRef] [PubMed]

4. Giarratana, F.; Muscolino, D.; Ragonese, C.; Beninati, C.; Sciarrone, D.; Ziino, G.; Mondello, L.; Giuffrida, A.; Panebianco, A. Antimicrobial activity of combined thyme and rosemary essential oils against Listeria monocytogens in Italian mortadella packaged in modified atmosphere: Thyme \& Rosemary EOs vs L. monocytogenes. J. Essent. Oil Res. 2016, 28, 467-474. [CrossRef] 
5. Vergis, J.; Gokulakrishnan, P.; Agarwal, R.K.; Kumar, A. Essential oils as natural food antimicrobial agents: A review. Crit. Rev. Food Sci. Nutr. 2015, 55, 1320-1323. [CrossRef] [PubMed]

6. Schmidt, E. Production of essential oils. In Handbook of Essential Oils: Science, Technology, and Applications, 3rd ed.; Husnu Can Baser, K., Buchbauer, G., Eds.; CRC Press: Boca Raton, FL, USA, 2020; pp. 83-90.

7. Calo, J.R.; Crandall, P.G.; O'Bryan, C.A.; Ricke, S.C. Essential oils as antimicrobials in food systems-A review. Food Control 2015, 54,111-119. [CrossRef]

8. Adorjan, B.; Buchbauer, G. Biological properties of essential oils: An updated review. Flavour Fragr. J. 2010, 25, 407-426. [CrossRef]

9. Bakkali, F.; Averbeck, S.; Averbeck, D.; Idaomar, M. Biological effects of essential oils-A review. Food Chem. Toxicol. 2008, 46, 446-475. [CrossRef]

10. Elsharkawy, E.R.; Ed-Dra, A.; Alghanem, S.; Abdallah, E.M. Comparative studies of chemical compostion, antimicrobial and antioxidant activity of essential oil of some species from genus Artemisia. J. Nat. Remedies 2018, 18, 10-20. [CrossRef]

11. Giarratana, F.; Muscolino, D.; Panebianco, F.; Patania, A.; Benianti, C.; Ziino, G.; Giuffrida, A. Activity of R (+) limonene against Anisakis larvae. Ital. J. Food Saf. 2015, 4. [CrossRef]

12. Pateiro, M.; Munekata, P.E.S.; Sant'Ana, A.S.; Domínguez, R.; Rodríguez-Lázaro, D.; Lorenzo, J.M. Application of essential oils as antimicrobial agents against spoilage and pathogenic microorganisms in meat products. Int. J. Food Microbiol. 2021, $337,108966$. [CrossRef] [PubMed]

13. Ed-Dra, A.; Filali, F.R.; Lo Presti, V.; Zekkori, B.; Nalbone, L.; Bouymajane, A.; Trabelsi, N.; Lamberta, F.; Bentayeb, A.; Giuffrida, A.; et al. Chemical composition, antioxidant capacity and antibacterial action of five Moroccan essential oils against Listeria monocytogenes and different serotypes of Salmonella enterica. Microb. Pathog. 2020, 149, 104510. [CrossRef] [PubMed]

14. Giarratana, F.; Muscolino, D.; Beninati, C.; Giuffrida, A.; Panebianco, A. Activity of Thymus vulgaris essential oil against Anisakis larvae. Exp. Parasitol. 2014, 142, 7-10. [CrossRef] [PubMed]

15. Nikolić, M.; Glamočlija, J.; Ferreira, I.C.F.R.; Calhelha, R.C.; Fernandes, Â.; Marković, T.; Marković, D.; Giweli, A.; Soković, M. Chemical composition, antimicrobial, antioxidant and antitumor activity of Thymus serpyllum L., Thymus algeriensis Boiss. and Reut and Thymus vulgaris L. essential oils. Ind. Crops Prod. 2014, 52, 183-190. [CrossRef]

16. Pesavento, G.; Calonico, C.; Bilia, A.R.; Barnabei, M.; Calesini, F.; Addona, R.; Mencarelli, L.; Carmagnini, L.; Di Martino, M.C.; Lo Nostro, A. Antibacterial activity of Oregano, Rosmarinus and Thymus essential oils against Staphylococcus aureus and Listeria monocytogenes in beef meatballs. Food Control 2015, 54, 188-199. [CrossRef]

17. Rota, M.C.; Herrera, A.; Martínez, R.M.; Sotomayor, J.A.; Jordán, M.J. Antimicrobial activity and chemical composition of Thymus vulgaris, Thymus zygis and Thymus hyemalis essential oils. Food Control 2008, 19, 681-687. [CrossRef]

18. Ozogul, Y.; Boğa, E.K.; Akyol, I.; Durmus, M.; Ucar, Y.; Regenstein, J.M.; Köşker, A.R. Antimicrobial activity of thyme essential oil nanoemulsions on spoilage bacteria of fish and food-borne pathogens. Food Biosci. 2020, 36, 100635. [CrossRef]

19. Ziani, K.; Chang, Y.; McLandsborough, L.; McClements, D.J. Influence of surfactant charge on antimicrobial efficacy of surfactantstabilized thyme oil nanoemulsions. J. Agric. Food Chem. 2011, 59, 6247-6255. [CrossRef]

20. Moazeni, M.; Davari, A.; Shabanzadeh, S.; Akhtari, J.; Saeedi, M.; Mortyeza-Semnani, K.; Abastabar, M.; Nabili, M.; Moghadam, F.H.; Roohi, B.; et al. In vitro Antifungal Activity of Thymus vulgaris Essential Oil nanoemulsion. J. Herb. Med. 2021, 100452. [CrossRef]

21. Thanissery, R.; Smith, D.P. Marinade with thyme and orange oils reduces Salmonella Enteritidis and Campylobacter coli on inoculated broiler breast fillets and whole wings. Poult. Sci. 2014, 93, 1258-1262. [CrossRef]

22. Oussalah, M.; Caillet, S.; Saucier, L.; Lacroix, M. Inhibitory effects of selected plant essential oils on the growth of four pathogenic bacteria: E. coli O157: H7, Salmonella typhimurium, Staphylococcus aureus and Listeria monocytogenes. Food Control 2007, 18, 414-420. [CrossRef]

23. Attia, R.A.; Mahmoud, A.E.; Farrag, H.M.M.; Makboul, R.; Mohamed, M.E.; Ibraheim, Z. Effect of myrrh and thyme on Trichinella spiralisenteral and parenteral phases with inducible nitric oxide expression in mice. Mem. Inst. Oswaldo Cruz 2015, 110, 1035-1041. [CrossRef] [PubMed]

24. Wu, L.; Huo, X.; Zhou, X.; Zhao, D.; He, W.; Liu, S.; Liu, H.; Feng, T.; Wang, C. Acaricidal activity and synergistic effect of thyme oil constituents against carmine spider mite (Tetranychus Cinnabarinus (Boisduval)). Molecules 2017, 22, 1873. [CrossRef]

25. World Health Organization. Food Safety. 2017. Available online: http://www.who.int/en/news-room/fact-sheets/detail/foodsafety (accessed on 16 June 2018).

26. EFSA Panel on Biological Hazards (BIOHAZ). Scientific Opinion on monitoring and assessment of the public health risk of "Salmonella Typhimurium-like" strains. EFSA J. 2010, 8, 1826. [CrossRef]

27. EFSA Panel on Biological Hazards (EFSA BIOHAZ Panel). Salmonella control in poultry flocks and its public health impact. EFSA J. 2019, 17, e05596. [CrossRef]

28. Doyle, M.P.; Diez-Gonzalez, F.; Hill, C. Food Microbiology: Fundamentals and Frontiers, 5th ed.; John Wiley \& Sons: Washington, DC, USA, 2020; pp. 225-262.

29. Ed-Dra, A.; Karraouan, B.; El Allaoui, A.; Khayatti, M.; El Ossmani, H.; Rhazi Filali, F.; ElMdaghri, N.; Bouchrif, B. Antimicrobial resistance and genetic diversity of Salmonella Infantis isolated from foods and human samples in Morocco. J. Glob. Antimicrob. Resist. 2018, 14, 297-301. [CrossRef]

30. Ed-Dra, A.; Filali, F.R.; Karraouan, B.; El Allaoui, A.; Aboulkacem, A.; Bouchrif, B. Prevalence, molecular and antimicrobial resistance of Salmonella isolated from sausages in Meknes, Morocco. Microb. Pathog. 2017, 105, 340-345. [CrossRef] 
31. Liu, Y.; Jiang, J.; Ed-Dra, A.; Li, X.; Peng, X.; Xia, L.; Guo, Q.; Yao, G.; Yue, M. Prevalence and genomic investigation of Salmonella isolates recovered from animal food-chain in Xinjiang, China. Food Res. Int. 2021, 110198. [CrossRef]

32. Murgia, M.; Bouchrif, B.; Timinouni, M.; Al-Qahtani, A.; Al-Ahdal, M.N.; Cappuccinelli, P.; Rubino, S.; Paglietti, B. Antibiotic resistance determinants and genetic analysis of Salmonella enterica isolated from food in Morocco. Int. J. Food Microbiol. 2015, 215, 31-39. [CrossRef]

33. Mejlholm, O.; Dalgaard, P. Antimicrobial effect of essential oils on the seafood spoilage micro-organism Photobacterium phosphoreum in liquid media and fish products. Lett. Appl. Microbiol. 2002, 34, 27-31. [CrossRef]

34. Giarratana, F.; Nalbone, L.; Ziino, G.; Giuffrida, A.; Panebianco, F. Characterization of the temperature fluctuation effect on shelf life of an octopus semi-preserved product. Ital. J. Food Saf. 2020, 9. [CrossRef]

35. Fennane, M.; Ibn Tattou, M.; Mathez, J.; Ouyahya, A.; EL Oualidi, J. Flore Pratique du Maroc. Manuel de Détermination des Plantes Vasculaires, 1.; Série Botanique, N., Ed.; Série Bota.; Travaux de l’Institut Scientifique: Rabat, Morocco, 1999.

36. Ed-Dra, A.; Filali, F.R.; Khayi, S.; Oulghazi, S.; Bouchrif, B.; El Allaoui, A.; Ouhmidou, B.; Moumni, M. Antimicrobial resistance, virulence genes, and genetic diversity of Salmonella enterica isolated from sausages. Eur. J. Microbiol. Immunol. 2019, 9, 56-61. [CrossRef]

37. Mazzarrino, G.; Paparella, A.; Chaves-López, C.; Faberi, A.; Sergi, M.; Sigismondi, C.; Compagnode, D.; Serio, A. Salmonella enterica and Listeria monocytogenes inactivation dynamics after treatment with selected essential oils. Food Control 2015, 50, 794-803. [CrossRef]

38. Silva-Angulo, A.B.; Zanini, S.F.; Rosenthal, A.; Rodrigo, D.; Klein, G.; Martínez, A. Comparative study of the effects of citral on the growth and injury of Listeria innocua and Listeria monocytogenes cells. PLoS ONE 2015, 10, e0114026. [CrossRef]

39. Giuffrida, A.; Giarratana, F.; Valenti, D.; Muscolino, D.; Parisi, R.; Parco, A.; Marotta, S.; Ziino, G.; Panebianco, A. A new approach to predict the fish fillet shelf-life in presence of natural preservative agents. Ital. J. Food Saf. 2017, 6. [CrossRef]

40. Baranyi, J.; Roberts, T.A. A dynamic approach to predicting bacterial growth in food. Int. J. Food Microbiol. 1994, 23, 277-294. [CrossRef]

41. Gumudavelli, V.; Subbiah, J.; Thippareddi, H.; Velugoti, P.R.; Froning, G. Dynamic predictive model for growth of Salmonella enteritidis in egg yolk. J. Food Sci. 2007, 72, 254-262. [CrossRef]

42. International Organization for Standardization. ISO 6579-1. Microbiology of the Food Chain-Horizontal Method for the Detection, Enumeration and Serotyping of Salmonella_Part 1: Detection of Salmonella spp; ISO: Geneva, Switzerland, 2017.

43. International Organization for Standardization. ISO 6658. Sensory Analysis-Methodology—General Guidance; International Organization for Standardization; ISO: Geneva, Switzerland, 2017.

44. International Organization for Standardization. ISO 8586. Sensory Analysis—General Guidelines for the Selection, Training and Monitoring of Selected Assessors and Expert Sensory Assessors; ISO: Geneva, Switzerland, 2012.

45. International Organization for Standardization. ISO 8589. Sensory Analysis-General Guidance for the Design of Test Rooms; International Organization for Standardization; ISO: Geneva, Switzerland, 2007.

46. Smaoui, S.; Hsouna, A.B.; Lahmar, A.; Ennouri, K.; Mtibaa-Chakchouk, A.; Sellem, I.; Najah, S.; Bouaziz, M.; Mellouli, L. Bio-preservative effect of the essential oil of the endemic Mentha piperita used alone and in combination with BacTN635 in stored minced beef meat. Meat Sci. 2016, 117, 196-204. [CrossRef] [PubMed]

47. Albarracín, W.; Sánchez, I.C.; Grau, R.; Barat, J.M. Salt in food processing; usage and reduction: A review. Int. J. Food Sci. 2011, 46, 1329-1336. [CrossRef]

48. Fadil, M.; Fikri-Benbrahim, K.; Rachiq, S.; Ihssane, B.; Lebrazi, S.; Chraibi, M.; Haloui, T.; Farah, A. Combined treatment of Thymus vulgaris L., Rosmarinus officinalis L. and Myrtus communis L. essential oils against Salmonella Typhimurium: Optimization of antibacterial activity by mixture design methodology. Eur. J. Pharm. Biopharm. 2018, 126, 211-220. [CrossRef]

49. Nezhadali, A.; Nabavi, M.; Rajabian, M.; Akbarpour, M.; Pourali, P.; Amini, F. Chemical variation of leaf essential oil at different stages of plant growth and in vitro antibacterial activity of Thymus vulgaris Lamiaceae, from Iran. Beni-Suef Univ. J. Basic Appl. Sci. 2014, 3, 87-92. [CrossRef]

50. Atti-Santos, A.C.; Pansera, M.R.; Paroul, N.; Atti-Serafini, L.; Moyna, P. Seasonal variation of essential oil yield and composition of Thymus vulgaris L. (Lamiaceae) from South Brazil. J. Essent. Oil Res. 2004, 16, 294-295. [CrossRef]

51. Abu-Darwish, M.S.; Aludatt, M.H.; Al-Tawaha, A.R.; Ereifej, K.; Almajwal, A.; Odat, N.; Al Khateeb, W. Seasonal variation in essential oil yield and composition from Thymus vulgaris L. during different growth stages in the south of Jordan. Nat. Prod. Res. 2012, 26, 1310-1317. [CrossRef] [PubMed]

52. Figueiredo, A.C.; Barroso, J.G.; Pedro, L.G.; Scheffer, J.J.C. Factors affecting secondary metabolite production in plants: Volatile components and essential oils. Flavour Fragr. J. 2008, 23, 213-226. [CrossRef]

53. Satyal, P.; Murray, B.; McFeeters, R.; Setzer, W. Essential oil characterization of Thymus vulgaris from various geographical locations. Foods 2016, 5, 70. [CrossRef]

54. Imelouane, B.; Amhamdi, H.; Wathelet, J.P.; Ankit, M.; Khedid, K.; El Bachiri, A. Chemical composition and antimicrobial activity of essential oil of thyme (Thymus vulgaris) from eastern Morocco. Int. J. Agric. Biol. 2009, 11, 205-208.

55. Pateiro, M.; Barba, F.J.; Domínguez, R.; Sant'Ana, A.S.; Khaneghah, A.M.; Gavahian, M.; Gomez, B.; Lorenzo, J.M. Essential oils as natural additives to prevent oxidation reactions in meat and meat products: A review. Food Res. Int. 2018, 113, 156-166. [CrossRef] 
56. Waraho, T.; McClements, D.J.; Decker, E.A. Mechanisms of lipid oxidation in food dispersions. Trends Food Sci. Technol. 2011, 22, 3-13. [CrossRef]

57. Amorati, R.; Foti, M.C.; Valgimigli, L. Antioxidant activity of essential oils. J. Agric. Food Chem. 2013, 61, 10835-10847. [CrossRef]

58. Kodal Coşkun, B.; Çalikoğlu, E.; Karagöz Emiroğlu, Z.; Candoğan, K. Antioxidant active packaging with soy edible films and oregano or thyme essential oils for oxidative stability of ground beef patties. J. Food Qual. 2014, 37, 203-212. [CrossRef]

59. Aljabeili, H.S.; Barakat, H.; Abdel-Rahman, H.A. Chemical Composition, Antibacterial and Antioxidant Activities of Thyme Essential Oil (Thymus vulgaris). Food Nutr. Sci. 2018, 09, 433-446. [CrossRef]

60. Lemos, M.F.; Lemos, M.F.; Pacheco, H.P.; Guimarães, A.C.; Fronza, M.; Endringer, D.C.; Scherer, R. Seasonal variation affects the composition and antibacterial and antioxidant activities of Thymus vulgaris. Ind. Crops Prod. 2017, 95, 543-548. [CrossRef]

61. Gedikoğlu, A.; Sökmen, M.; Çivit, A. Evaluation of Thymus vulgaris and Thymbra spicata essential oils and plant extracts for chemical composition, antioxidant, and antimicrobial properties. Food Sci. Nutr. 2019, 7, 1704-1714. [CrossRef]

62. Paulus, D.; Luchesi, L.A.; Busso, C.; Frata, M.T.; Oliveira, P.J.B. de Chemical Composition, Antimicrobial and Antioxidant Activities of Essential Oils of Four Species of the Lamiaceae Family. Eur. J. Med. Plants 2020, 129-140. [CrossRef]

63. Aeschbach, R.; Löliger, J.; Scott, B.C.; Murcia, A.; Butler, J.; Halliwell, B.; Aruoma, O.I. Antioxidant actions of thymol, carvacrol, 6-gingerol, zingerone and hydroxytyrosol. Food Chem. Toxicol. 1994, 32, 31-36. [CrossRef]

64. Foti, M.C.; Ingold, K.U. Mechanism of inhibition of lipid peroxidation by $\gamma$-terpinene, an unusual and potentially useful hydrocarbon antioxidant. J. Agric. Food Chem. 2003, 51, 2758-2765. [CrossRef]

65. Guo-Xiang, L.; Zai-Qun, L. Unusual antioxidant behavior of $\alpha$ - and $\lambda$-terpinene in protecting methyl linoleate, DNA, and erythrocyte. J. Agric. Food Chem. 2009, 57, 3943-3948. [CrossRef]

66. Milde, J.; Elstner, E.F.; Graßmann, J. Synergistic inhibition of low-density lipoprotein oxidation by rutin, $\gamma$-terpinene, and ascorbic acid. Phytomedicine 2004, 11, 105-113. [CrossRef]

67. Dahham, S.S.; Tabana, Y.M.; Iqbal, M.A.; Ahamed, M.B.K.; Ezzat, M.O.; Majid, A.S.A.; Majid, A.M.S.A. The anticancer, antioxidant and antimicrobial properties of the sesquiterpene $\beta$-caryophyllene from the essential oil of Aquilaria crassna. Molecules 2015, 20, 11808-11829. [CrossRef]

68. Bajpai, V.K.; Baek, K.H.; Kang, S.C. Control of Salmonella in foods by using essential oils: A review. Food Res. Int. 2012, 45, 722-734. [CrossRef]

69. Guarda, A.; Rubilar, J.F.; Miltz, J.; Galotto, M.J. The antimicrobial activity of microencapsulated thymol and carvacrol. Int. J. Food Microbiol. 2011, 146, 144-150. [CrossRef]

70. Sato, K.; Krist, S.; Buchbauer, G. Antimicrobial effect of vapours of geraniol, (R)-(-)-linalool, terpineol, $\gamma$-terpinene and 1,8-cineole on airbone microbes using an airwasher. Flavour Fragr. J. 2007, 22, 435-437. [CrossRef]

71. Bartkiene, E.; Ruzauskas, M.; Bartkevics, V.; Pugajeva, I.; Zavistanaviciute, P.; Starkute, V.; Zokaityte, E.; Lele, V.; Dauksiene, A.; Grashorn, M.; et al. Study of the antibiotic residues in poultry meat in some of the EU countries and selection of the best compositions of lactic acid bacteria and essential oils against Salmonella enterica. Poult. Sci. 2020, 99, 4065-4076. [CrossRef] [PubMed]

72. Sartoratto, A.; Machado, A.L.M.; Delarmelina, C.; Figueira, G.M.; Duarte, M.C.T.; Rehder, V.L.G. Composition and antimicrobial activity of essential oils from aromatic plants used in Brazil. Braz. J. Microbiol. 2004, 35, 275-280. [CrossRef]

73. Marotta, S.M.; Giarratana, F.; Parco, A.; Neri, D.; Ziino, G.; Giuffrida, A.; Panebianco, A. Evaluation of the antibacterial activity of bergamot essential oils on different Listeria monocytogenes strains. Ital. J. Food Saf. 2016, 5. [CrossRef]

74. Burt, S. Essential oils: Their antibacterial properties and potential applications in foods-A review. Int. J. Food Microbiol. 2004, 94, 223-253. [CrossRef]

75. Hayouni, E.A.; Chraief, I.; Abedrabba, M.; Bouix, M.; Leveau, J.Y.; Mohammed, H.; Hamdi, M. Tunisian Salvia officinalis L. and Schinus molle L. essential oils: Their chemical compositions and their preservative effects against Salmonella inoculated in minced beef meat. Int. J. Food Microbiol. 2008, 125, 242-251. [CrossRef]

76. Stojanović-Radić, Z.; Pejčić, M.; Joković, N.; Jokanović, M.; Ivić, M.; Šojić, B.; Škaljac, S.; Stojanović, P.; Mihajilov-Krstev, T. Inhibition of Salmonella Enteritidis growth and storage stability in chicken meat treated with basil and rosemary essential oils alone or in combination. Food Control 2018, 90, 332-343. [CrossRef]

77. Nieto, G. A Review on Applications and Uses of Thymus in the Food Industry. Plants 2020, 9, 961. [CrossRef]

78. Huang, Z.; Liu, X.; Jia, S.; Zhang, L.; Luo, Y. The effect of essential oils on microbial composition and quality of grass carp (Ctenopharyngodon idellus) fillets during chilled storage. Int. J. Food Microbiol. 2018, 266, 52-59. [CrossRef]

79. Boutoial, K.; García, V.; Rovira, S.; Ferrandini, E.; Abdelkhalek, O.; López, M.B. Effect of feeding goats with distilled and non-distilled thyme leaves (Thymus zygis subp. gracilis) on milk and cheese properties. J. Dairy Res. 2013, 80, 448. [CrossRef]

80. Boskovic, M.; Djordjevic, J.; Ivanovic, J.; Janjic, J.; Zdravkovic, N.; Glisic, M.; Glamoclija, N.; Baltic, B.; Djordjevic, V.; Baltic, M. Inhibition of Salmonella by thyme essential oil and its effect on microbiological and sensory properties of minced pork meat packaged under vacuum and modified atmosphere. Int. J. Food Microbiol. 2017, 258, 58-67. [CrossRef]

81. Van Haute, S.; Raes, K.; Van der Meeren, P.; Sampers, I. The effect of cinnamon, oregano and thyme essential oils in marinade on the microbial shelf life of fish and meat products. Food Control 2016, 68, 30-39. [CrossRef] 